Check for updates

Cite this: Mater. Adv., 2021, 2,1872

Received 21st January 2021 Accepted 1st February 2021

DOI: $10.1039 / \mathrm{d} 1 \mathrm{ma} 00049 \mathrm{~g}$

rsc.li/materials-advances

\section{Recent advances in nanocellulose processing, functionalization and applications: a review}

\author{
Vaishali Thakur, ${ }^{a}$ Ashish Guleria, ${ }^{b}$ Sanjay Kumar, ${ }^{c}$ Shikha Sharma ${ }^{d}$ and \\ Kulvinder Singh (D)*a
}

In recent years, environmental and ecological concerns have become a major issue owing to the expansion of petroleum-based synthetic materials and products, and therefore the development of novel and effective synthetic materials that have ecofriendly and economical properties is of significant interest. With the improvements in nanotechnology, biopolymer nanocellulose has gained further attention owing to its remarkable properties and easy availability from various plant species and agricultural waste products, such as rice husk, tea leaves, sugarcane bagasse and so forth. Nanocellulosic materials have wider applications, for example they are used in bio-sensing, catalysis, wastewater treatment, drug delivery, tissue engineering, flame retardants and so on, owing to their long-lasting nature, anisotropic shape, splendid biocompatibility, potent surface chemistry, and efficacious mechanical and optical properties. Chemical, mechanical, physicochemical and enzymatic pretreatments can be utilized to synthesize nanocellulose from cellulosic waste. The features of nanocellulosic materials are mainly dependent on the extraction technique, source and efficient subsequent surface functionalization. Surface functionalization of nanocellulosic materials involves various routes of functionalization, for example, to provide ionic charges on the surface of nano-cellulose via phosphorylation, carboxymethylation, oxidation and sulfonation on nanocellulosic surfaces, or to generate a hydrophobic surface on a nanocellulosic material via acetylation, etherification, silylation, urethanization and amidation. Functionalization of nanocellulose through grafting of a polymer onto its backbone is also an interesting route owing to its wider applications in various dimensions. These modifications provide potential nanomaterials which can be utilized as reinforcing agents in various nanocomposites and also promotes specific features for the production of novel cellulosic nanomaterials, with the objective of promoting their applications in the field of functionalized nanomaterials.

\section{Introduction}

Cellulose is the predominant component of the plant cell wall and can be acquired from several sources, such as agriculture waste, wood, fibers, plants and so on. Apart from the cellulose they also contain hemicellulose, lignin, and some extractives in minor proportions. ${ }^{1-3}$ Owing to effectual and easier routes of delignification and purification, in the case of cellulosic agricultural byproducts, these are considered to be a superior source of cellulosic content. ${ }^{1,4,5}$ Cellulose is an environmentally friendly, biocompatible, and cost effective natural polymer and owing to this it is currently widely adopted for the treatment of wastewater

\footnotetext{
${ }^{a}$ Department of Chemistry, Maharaja Agrasen University, Baddi, Himachal Pradesh, 174103, India. E-mail: kulvinderchem@gmail.com, kulvinderchem@mau.edu.in

${ }^{b}$ Department of Applied Sciences, WIT Dehradun, 248007, India

${ }^{c}$ Department of Chemistry, Govt. College Drang at Narla, Mandi,

Himachal Pradesh, India

${ }^{d}$ Department of Botany, Post Graduate Government College for Girls, Sector 11, 160011, Chandigarh, India
}

through the adsorption technique. ${ }^{6-8}$ With the evolution of nanotechnology, nanocellulose has attracted more attention and is preferred as it is an efficacious and energy-saving material. Nanocellulose is also preferred for large scale applications such as manufacturing substances for essential materials in food, paints, textiles and pharmaceutical applications. ${ }^{9,10}$ Nowadays effective applications of nanocellulose are preferred at the nanostructure level for generating various biocompatible materials and also a variety of productive cellulose derivatives. ${ }^{6,11}$ Owing to the nanostructure, nanocellulose has effective physical properties and potent surface chemistry. ${ }^{12}$ Recently, nanocellulose has gained interest in the fields of material and biomedical sciences owing to its long lasting nature, anisotropic shape, favorable mechanical properties, splendid biocompatibility, potent surface chemistry, and efficacious optical properties. ${ }^{13-15}$ In recent years, nanocellulose has been explored for use in many applications such as films, photonics, surface functionalization, nano-composites, adaptable optoelectronics and medical sciences, for example, scaffolds in tissue regeneration. ${ }^{16,17}$ The main favorable quality 


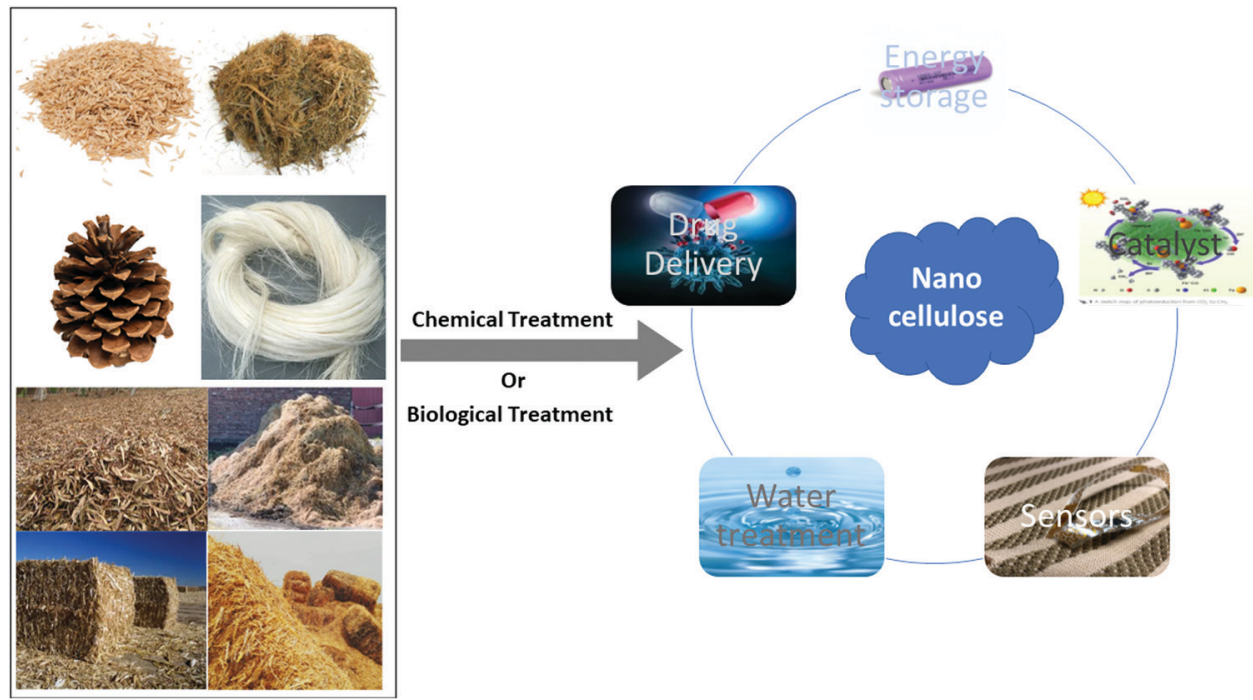

Fig. 1 Pictorial representation of the synthesis and applications of nanocellulose.

of nanocellulose is the environmentally friendly nature of the particles and their efficacious chemical and physical properties and the homogeneity of substances that can be extracted from this biomaterial. ${ }^{8,11}$

Several mechanical, physical and chemical treatments have been considered, although the favorable formation of nanocellulose still proceeds with an unfavorable chemical pre-treatment. ${ }^{18-23}$ Thus, to advance research into the efficacious applications of nanocellulose, it is essential to generate durable and environmentally friendly processing pre-treatment methods (Fig. 1). ${ }^{16}$

Therefore, advanced research is needed to understand the many latest advances, such as certain expulsion methods, quality estimation of the cellulose micro/nano-fibril, the enzymatic pre-treatment routes and so on. ${ }^{24,25}$ This review compiles these studies to differentiate the several routes used for the extraction of cellulose and then recommends an efficacious, eco-friendly and sustainable superior route for the extraction..$^{16,18,21,26-28}$ Some routes of functionalization possess many major drawbacks, such as the generation of a large quantity of acid containing water during acid hydrolysis, greater energy requirements during mechanical pre-treatments and greater time consumption during the reaction of enzymatic hydrolysis. Owing to these drawbacks the present study emphasizes the superior routes of functionalization, which are efficacious, economical and sustainable. This review recapitulates the studies for the surface functionalization of nanocellulosic materials. The first route for the functionalization is to provide an ionic surface on the nano-cellulosic material, such as the phosphorylation, carboxymethylation, oxidation and sulfonation routes used on nanocellulosic surfaces. The second route is to generate a hydrophobic surface on the nanocellulosic material, such as the acetylation, etherification, silylation, urethanization and amidation routes. ${ }^{29-31}$ The third route for the functionalization of nanocellulose is the grafting of a polymer on its backbone via the grafting to, grafting from and grafting through routes of polymer grafting. Free radical, atom transfer radical polymerization (ATRP), ring opening polymerization (ROP) and reversible addition-fragmentation chain transfer (RAFT) methods are the types of grafting used in this route. ${ }^{8,29,30,32}$ Owing to the wider applications of nanocellulose, it is one of the most preferred biomaterials for development. Its wider applications include hydrogels, aerogels of nanocellulosic materials, nano-carbon composites, nanocellulosic carbon quantum-dot based composites, nanocellulosic carbon nanotube based composites, nanocellulosic graphene based materials, nanocellulosic organic polymer matrices, nanocellulosic inorganic nano-composites ${ }^{11,17,31-34}$ and nanogels that are composed of biopolymers or hydrogels and act as a crosslinker hydrophilic polymer and thus have wider applications. These applications include medical imaging, sensors, nanoactuators, delivering and the loading of proteins into the cell to enhance its stability, for example polyethylenimine based nanogels are used to deliver anticancer components into cells. ${ }^{35-42}$ The properties of nanogels include swelling, chemical functionality and degradation, which can be controlled by the filling of pores in nanogels with small macromolecules or monomers. ${ }^{43-45}$ The present study focuses on the morphology and structure of nano structured cellulose and its classification, that is micro/nano fibrillated, nanocrystal-based cellulose, and bacterial/microbial based nanocellulose. This review also recapitulates the many advances in nanocellulosic materials in waste water treatment, biosensors, catalysis, adsorption and so on. ${ }^{17,30}$

\subsection{Morphology and structure of nano structured cellulose}

Nanostructured based cellulose $\left(\left(\mathrm{C}_{6} \mathrm{H}_{10} \mathrm{O}_{5}\right)_{n}\right)$ is a long chain homoglycans or homo-polysaccharide containing dextrose (D-glucose) unit with repeating units of $\mathrm{C}_{12} \mathrm{H}_{22} \mathrm{O}_{11}$ (cellobiose), in which two glucose $\left(\mathrm{C}_{6} \mathrm{H}_{12} \mathrm{O}_{6}\right)$ molecules are linked, resulting in the formation of a $\beta-1,4$ glycosidic linkage. ${ }^{46}$ Cellulose $\left(\mathrm{C}_{6} \mathrm{H}_{10} \mathrm{O}_{5}\right)_{n}$ has a complex composition of $\beta$-D-glucose/glucopyranose structures that has a ${ }^{4} \mathrm{C}_{1}$ chair-conformation. ${ }^{9,10}$ The active hydroxyl $(-\mathrm{OH})$ functional groups are adjacent to the backbone of cellulose and are aligned towards the equatorial positions of the ring, although the hydrogen-atoms are aligned towards the 

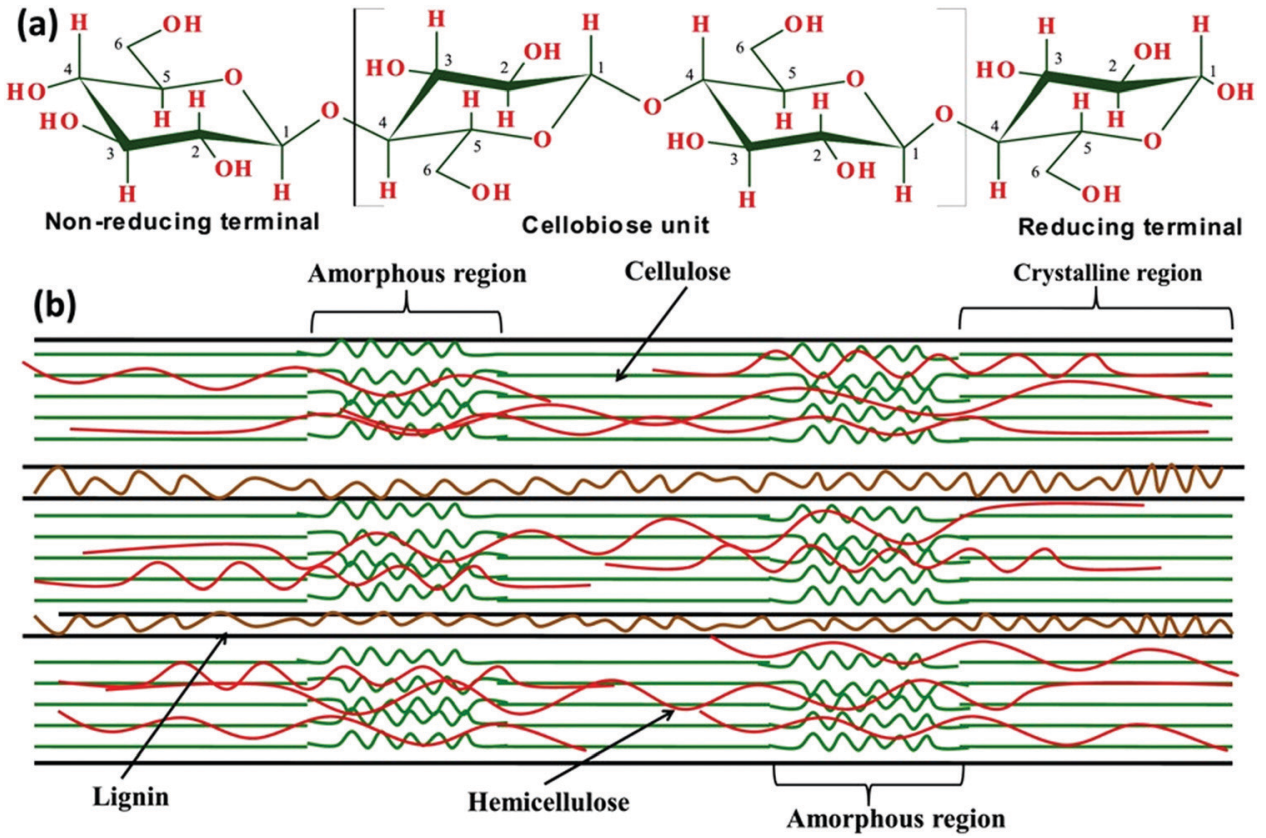

Fig. 2 (a) Linear structure of cellulose showing three hydroxyl $(-\mathrm{OH})$ groups situated at the $C^{2}, C^{3}$ and $C^{6}$ atoms of each $\beta$-D-glucopyranose unit, and (b) composite structure of the lignocellulosic biomass with amorphous and crystalline regions. Adapted with permission from ref. 5 . Copyright 2017 Elsevier.

axial positions. ${ }^{29}$ This orientation of cellulose $\left(\mathrm{C}_{6} \mathrm{H}_{10} \mathrm{O}_{5}\right)_{n}$ is stabilized by the intra-molecular hydrogen-bonding. ${ }^{30}$ The degree of polymerization and kinetic chain length of the cellulose based nanostructured materials depends on the composition of the cellulosic material. ${ }^{47}$ It was revealed that cellulose derived from wood constitutes almost 10000 glucose/glucopyranose $\left(\mathrm{C}_{6} \mathrm{H}_{12} \mathrm{O}_{6}\right)$ units, whereas cotton based cellulose has approximately 15000 glucose $\left(\mathrm{C}_{6} \mathrm{H}_{12} \mathrm{O}_{6}\right)$ units. ${ }^{48,49}$ The illustrative depiction of the cellulose in the crystalline form reveals its chemical composition, which represents the intra and inter-molecular H-bonds in the ring, as shown in Fig. 2. ${ }^{5,11}$ The nano structured forms of cellulose, such as micro-fibrillated celluloses (MFCs) and nanocrystal-based celluloses (CNCs), have been produced from several cellulosic sources, for example corn-cobs, cotton, rice husks, bamboo culm, bamboo wood pulp and so on. ${ }^{29}$

\subsection{Classification of biopolymer nanocellulose}

Biopolymer nanocellulose is classified into different forms based on the source and dimensions. The size range of biopolymer nanocellulose varies with different raw materials and the processing pre-treatments used. Mainly, nanocellulose can be classified into nanofibers and nanostructured materials. The nanostructured materials comprise cellulose microfibrils and microcrystalline cellulose (MCC), on the other hand nanofibers can be further categorized into MFCs and nano-fibrillated cellulose (NFCs), CNCs, and bacterial/microbial based nanocelluloses (BNCs/MNCs) as shown in Fig. $3 .^{50} \mathrm{MCC}$ is a term used for processed wood pulp and it is used in food processing as a texturizer, anti-caking agent, fat substitute, emulsifier, extension, and a bulking agent. In vitamin supplements or tablets, the most common form is opted, a microfibril cellulose composed of glycoproteins and cellulose and it is a very fine fibril. In defining the protein fiber structure, for example in hair and sperm tails, it is often, but not always, used as a general term. The $9+2$ pattern in which two central protofibrils are surrounded by nine other pairs is their most commonly observed structural pattern, ${ }^{51,52}$ it is also used for counting viruses in plaque assays as an alternative to carboxymethylcellulose. CNCs, widely synthesized using acid hydrolysis treatment, comprise elongated, cylindrical, rod like and lesser flexible nanoparticles having a width of 4-70 nm, a length of 100-6000 nm and a crystallinity index of $54-88 \%$. NFCs are synthesized from macromolecules of cellulose having a diameter range of $5-30 \mathrm{~nm}$ in an expanded chain conformation. ${ }^{51,53}$ The biopolymer chain of nanocellulose with building blocks is obtained from D-glucopyranose molecules which are interlinked by the $\beta-1,4$-glucosidic bond. The vital difference between the CNFs and CNCs resides in the portion of the amorphous media, size and features of the material, these parameters are influenced by the isolation condition. Broadly, the best method used for the isolation of CNCs is acid hydrolysis treatment. This route involves a strong acid $\left(\mathrm{H}_{2} \mathrm{SO}_{4}\right)$ that disintegrates the amorphous phase (disordered regions) of the cellulosic material, then the nanocrystal structure of cellulose is formed. The crystallinity and size of the CNCs are influenced by the cellulosic source and isolation conditions. ${ }^{52}$ Although, CNFs are widely synthesized via the mechanical delamination route through aqueous suspensions of cellulosic pulp in a high-pressure homogenizer (HPH). During the synthesis of CNFs, an extremely intertwined matrix of nanofibrils, having both amorphous and crystalline phases, is formulated owing to the large shear force used. ${ }^{54}$ By controlling the reaction parameters, CNFs can be decomposed into versatile nanofibers having a diameter of 


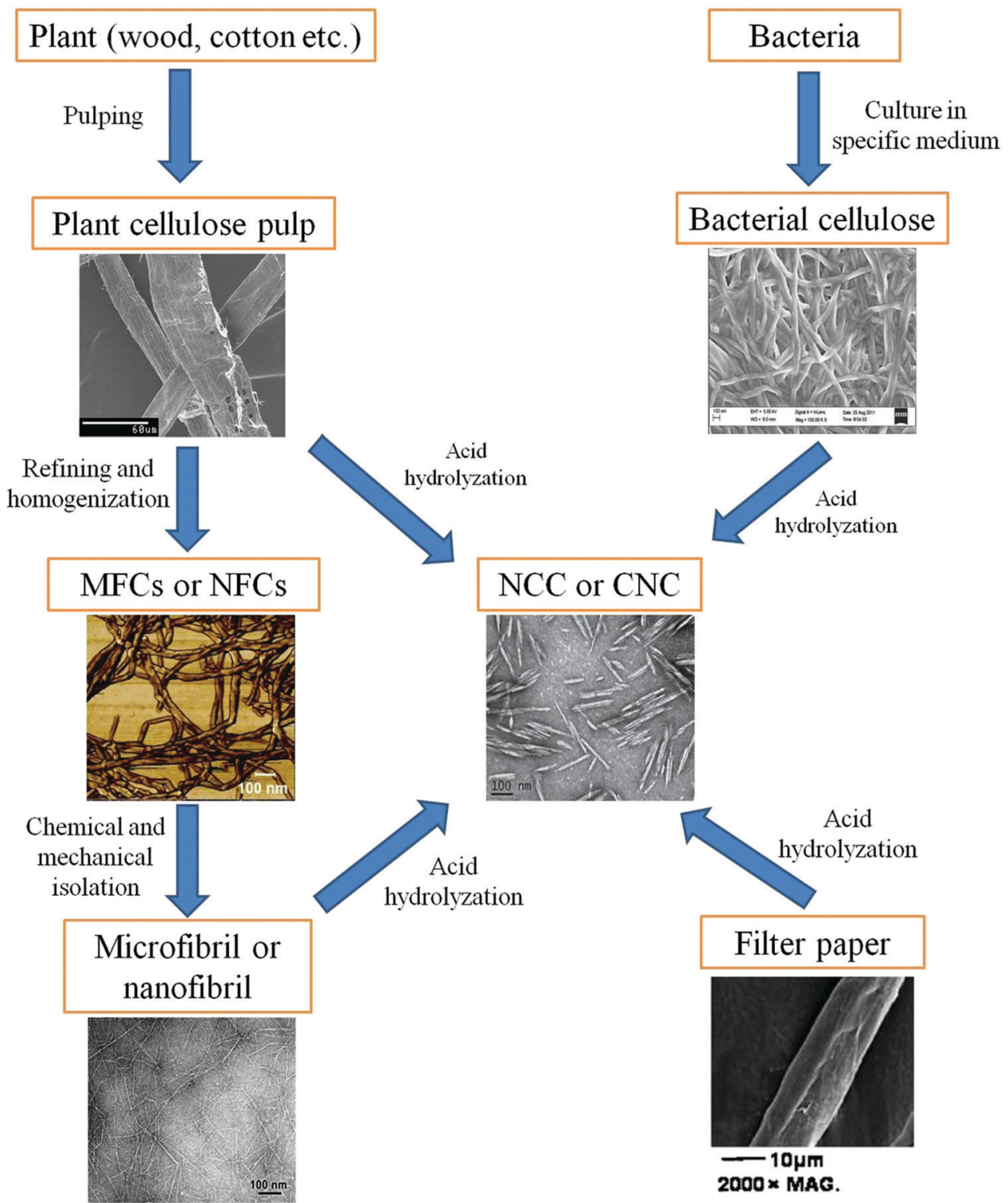

Fig. 3 Relationship between different types of nanocelluloses. Adapted with permission from ref. 50. Copyright 2014 Royal Society of Chemistry.

20-50 $\mathrm{nm}$ and a length of 500-2000 nm. ${ }^{54,55}$ The types of nanofibers are briefly discussed below. ${ }^{56,57}$

1.2.1. Micro/nano-fibrillated cellulose. Micro/nano-fibrillated celluloses are also termed as cellulose based micro-fibrillar cellulose, nano-fibrillar cellulose, as well as cellulose nanofibers. ${ }^{15,58-60}$ These fibers constitute a large cluster of micro-fibrils that involve both amorphous and crystalline forms of nanostructured cellulose owing to which a rigid network composition is attainted. NFCs have a large aspect ratio with a fine thickness of 20-60 nm (nanometers) and the diameter of around a few micro-meters $(\mu \mathrm{m})$ is almost $10 \mu \mathrm{m}$ (Fig. 4). ${ }^{27,61,62}$ The NFCs are extracted from plants, agricultural waste, cotton, fibers and so on. ${ }^{63,64}$ The size range of these nanomaterials varies with the source of cellulosic materials. ${ }^{58}$

1.2.2. Cellulose based nanocrystals. Cellulose based nanocrystals are also termed as cellulose based nanoparticles (CNPs) that are produced from cellulose based different raw materials by using acid hydrolysis treatments. Another name for cellulose based nano-crystals is nanowhiskers as they are cylindrical, enlarged and have a rod like composition with a thickness of around $5-70 \mathrm{~nm}$ and a diameter of almost $100 \mathrm{~nm}$ to some micrometers. ${ }^{65,66}$ Cellulose based nanocrystals are generally narrow and shorter in size than cellulose based MFCs, as shown in Fig. 5. ${ }^{67}$ The cylinder like composition of crystalline nanostructured cellulose is attained when all the non-cellulose based polysaccharide $\left(\mathrm{C}_{x}\left(\mathrm{H}_{2} \mathrm{O}\right)_{y}\right)$ contents have been eliminated from the fibrillar surface and after the cleavage of all bonds in the amorphous forms of cellulosic material. ${ }^{9} \mathrm{CNCs}$ form dispersions in aqueous solutions and organic mixtures, whereas particle accumulation occurs in maximum hydrophobic mixtures of the solutions. ${ }^{55,68}$

1.2.3. Bacterial/microbial based nanocellulose. In contrast to plant varieties, extra cellular nanostructured cellulose can be 

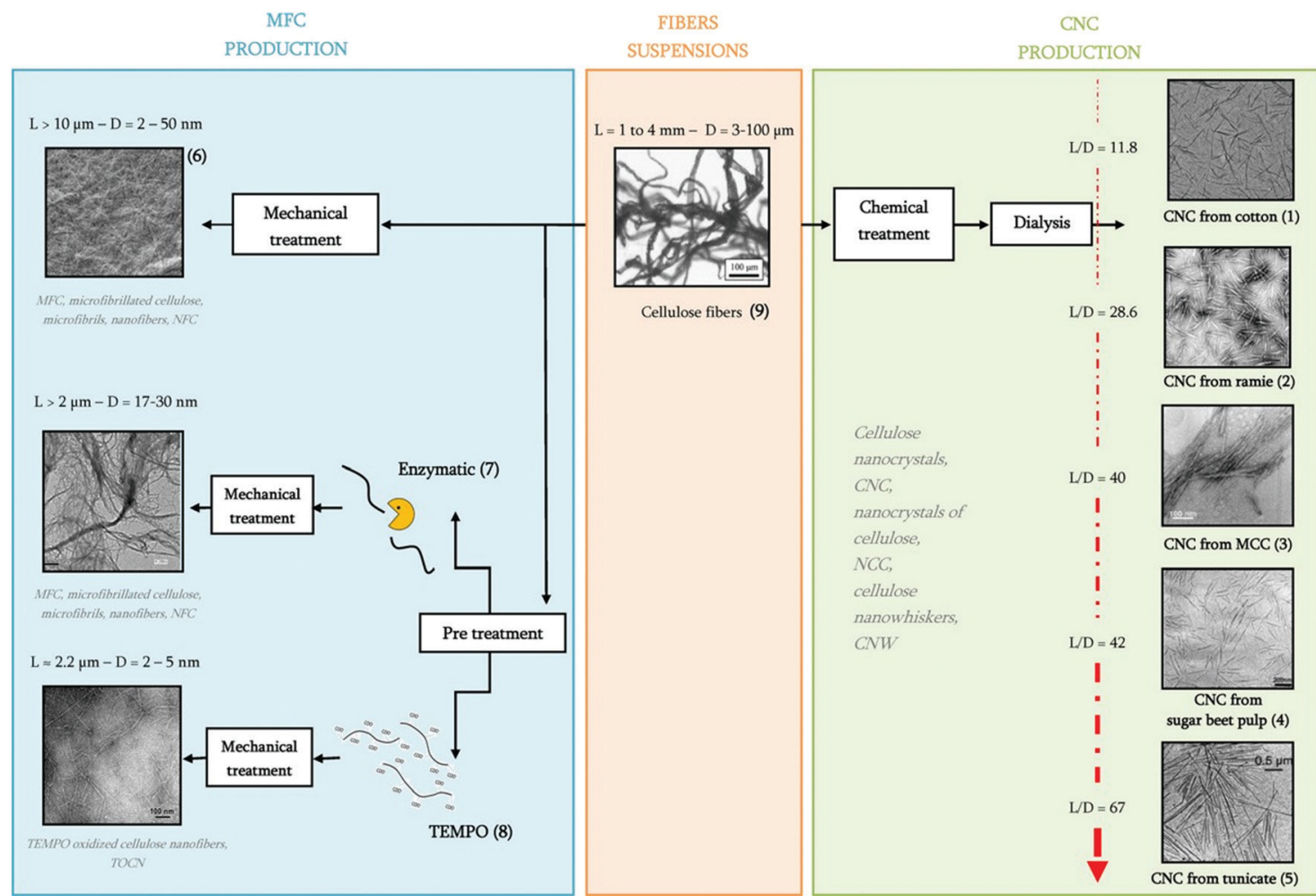

Fig. 4 From fiber suspensions to nanocelluloses with their various terminologies. Adapted with permission from ref. 27. Copyright 2012 Elsevier.

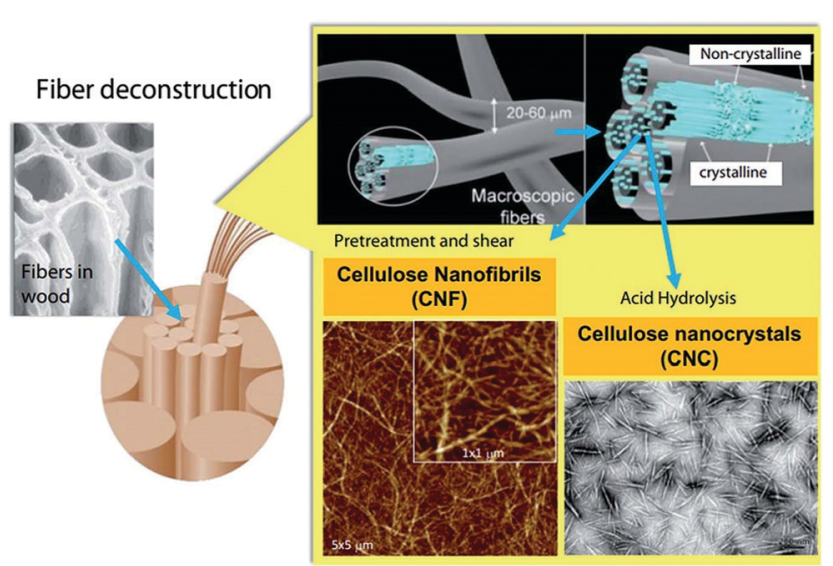

Fig. 5 Schematic illustration of the production of CNFs and CNCs from fiber cell walls by mechanical and chemical treatments, respectively. Adapted with permission from ref. 67 Copyright 2019 Royal Society of Chemistry.

extracted from several bacterial or microbial species (Rhizobium, Agrobacterium, Pseudomonas and Acetobacter etc.). ${ }^{15,69,70}$ Although, cellulose is also synthesized from various bacterial sources (actinomycetes and fungi). Biopolymer cellulose is obtained from bacterial sources (actinomycetes and fungi) having a diameter range of around 20-100 $\mathrm{nm}$ (nano-meters) and a thickness of 100-300 $\mathrm{nm}$ that varies with the growing conditions, the kind of bacterial strain, and the bio-reactor used. ${ }^{71}$ BNCs or MNCs are the type of pure nanostructured cellulose attained by the agglomeration of cellulose fibrillars. ${ }^{46,62}$
1.2.4. Spherical nanocellulose (SNC). Spherical nanocellulose has a sphere like shape, possessing a cellulose II type crystal structure, extracted from waste materials via treatment with $\mathrm{NaOH}$ and thiourea $\left(\mathrm{CH}_{4} \mathrm{~N}_{2} \mathrm{~S}\right)$ or urea $\left(\mathrm{CH}_{4} \mathrm{~N}_{2} \mathrm{O}\right)$ which is a cost effective and environmentally friendly approach. ${ }^{72}$ Ram et al. demonstrated the synthesis of a cellulose based modified adsorbent for the removal of mercuric ions via acid treatment with lipase catalyzed esterification through 3-mercaptopropionic acid. ${ }^{73}$ The extraction of spherical nanocellulose was reported using an anaerobic microbial consortium via hydrolysis of nanocrystalline cellulose, derived from cotton fibers. ${ }^{74}$ The isolated spherical nanocellulose was obtained when the process of degradation of nano-crystalline cellulose was purified via a differential centrifugation approach and separated through an ultra-filtration technique (Fig. 6). ${ }^{73,75,76}$

\subsection{Methodologies for the isolation of nanocellulose}

Agriculture waste materials, plants and other materials containing cellulosic content are utilized as an effective material in wider applications owing to their economical, eco-friendly, biodegradable and other efficacious properties. ${ }^{7-79}$ The various routes for the isolation of nanocellulose involves chemical routes, enzymatic methods, mechanical routes and physicochemical routes of isolation. $^{30}$

For the isolation of nanocellulose, some of the main parameters that are considered before selection of the particular route of extraction are the porosity, crystallinity, surface area and chain length of nanocellulose. ${ }^{11}$ Several routes for the isolation of nanocellulose are briefly discussed in this section. Various 


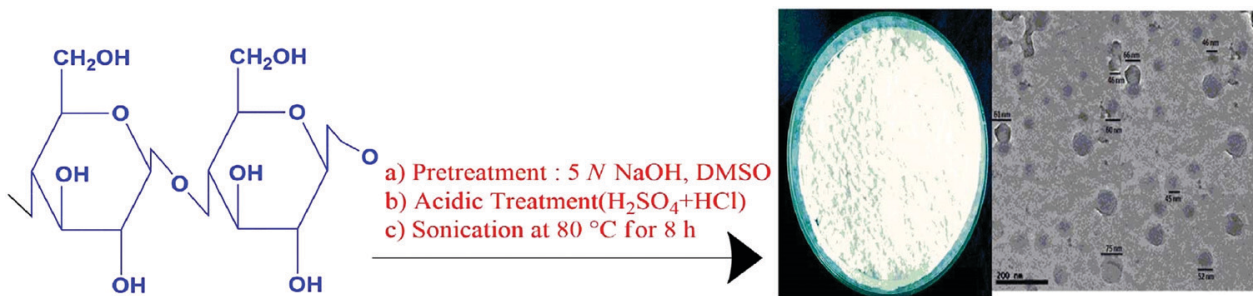

Cellulose

Spherical nanocellulose

Fig. 6 Synthetic route for spherical nanocellulose via acid hydrolysis. Adapted with permission from ref. 73. Copyright 2017 Elsevier.

sources, types, dimensions and different treatments for the isolation of biopolymer nanocellulose are shown in Table $1^{4,80-89}$ and Table 2. ${ }^{65,82,90-95}$

1.3.1. Chemical routes of isolation. Chemical routes for the isolation of nanocellulose from nanocellulosic materials include the alkaline pre-treatment, acid pre-treatment, oxidation, pretreatment via ionic solvents and various solvent isolation routes. ${ }^{8}$ The alkaline route of delignification involves pre-treatment using alkalis, for example, $\mathrm{NaOH}$ (sodium hydroxide), $\mathrm{KOH}$ (potassium hydroxide), $\mathrm{Ca}(\mathrm{OH})_{2}$ (calcium hydroxide), $\mathrm{NH}_{3}$ (ammonia) and $\mathrm{Na}_{2} \mathrm{CO}_{3}$ (sodium carbonate). Out of all the alkaline reagents, $\mathrm{NH}_{3}$ is preferred as a best candidate to reduce the hydrolysis reaction of cellulose. ${ }^{96}$ In an alkaline route, the delignification process is liable for the decrystallization of the cellulosic material, the higher surface area, reduced degree of polymerization and the porosity of cellulose. This treatment requires a significantly reduced temperature and pressure with easy recovery of the alkali reagent upon completion of the reaction. However, owing to the demand for highly concentrated alkaline reagents and the long reaction time, it has major drawbacks in the isolation process. ${ }^{5,97,98}$ On the other hand, the acid route involves dilute and concentrated acids such as $\mathrm{HCl},{ }^{99} \mathrm{H}_{3} \mathrm{PO}_{4},{ }^{100} \mathrm{HNO}_{3}{ }^{101}$ oxalic, ${ }^{102}$ maleic $^{103}$ and some heteropoly-acids (HPAs) for the isolation of nanocellulose. ${ }^{104}$ The main parameters which play major roles in the acid pretreatment are the concentration of the acid, the degradation temperature and the acid cellulosic waste ratio. The acid route possesses a major drawback owing to the toxic and corrosive nature of concentrated acids. ${ }^{8,105,106}$ Another route for the isolation of nanocellulose is oxidation, which involves ozonolytic treatment via $\mathrm{H}_{2} \mathrm{O}_{2}$ (hydrogen peroxide) $\mathrm{O}_{2}$ (dioxygen) and $\mathrm{O}_{3}$ (ozone) to enable the delignification process. Ozone is one of the best agents in the delignification process, owing to the $\mathrm{H}_{2} \mathrm{O}$ soluble properties it mainly attacks the conjugated $\mathrm{C}=\mathrm{C}$ bonds and aromatic compounds. ${ }^{107-109}$ Wet oxidation is the preferred oxidation process because it removes $50-60 \%$ of the lignin content from cellulosic waste and proceeds in either air or oxygen in the presence of $\mathrm{H}_{2} \mathrm{O}$ at a pressure and temperature of 5-20 MPa and 150-350 ${ }^{\circ} \mathrm{C}$ respectively. ${ }^{106,110,111}$ Although there are some other pretreatments via which nanocellulose can be extracted, such as the pretreatment of ionic solvents, which is a mixture of higher organic cations and lower inorganic anions, ${ }^{105,112-116}$ solvent extraction pretreatment is also used for the extraction of nanocellulose in which various solvents are applied, for example methanol $(\mathrm{MeOH})$, ethanol (EtOH), butanol $\left(\mathrm{C}_{4} \mathrm{H}_{9} \mathrm{OH}\right)$, triethylene glycol $\left(\mathrm{C}_{6} \mathrm{H}_{14} \mathrm{O}_{4}\right)$, tetrahydrofuran $\left(\mathrm{C}_{4} \mathrm{H}_{8} \mathrm{O}\right)$ ethers, ketones, benzene $\left(\mathrm{C}_{6} \mathrm{H}_{6}\right)$ and so forth. ${ }^{117-119}$ However, this pretreatment method possesses major drawbacks, such as the high cost of organicsolvents and the instrumental setup, and the volatile organic solvents restrict its demand for industrial applications. ${ }^{8}$ Scanning electron microscopy (SEM) analysis of SCD (supercritical drying) nanocellulose aerogels exhibited a 3D nano-structured network consisting of randomly arranged nanofibrils (Fig. 7). ${ }^{120}$

Table 1 List of various sources of biopolymer nanocellulose, their isolation treatments, the isolated MFCs and NFCs and their dimensions

\begin{tabular}{|c|c|c|c|}
\hline Cellulosic source & Treatments for isolation of nanocellulose & Dimensions of biopolymer nanocellulose & Ref. \\
\hline Bamboo wood pulp or culm & Chemical treatment with $64 \% \mathrm{H}_{2} \mathrm{SO}_{4}$ & 30-40 nm longer cylindrical fibrils & 80 \\
\hline Rachis of banana & $\begin{array}{l}\text { Chemical treatment with } \mathrm{H}_{2} \mathrm{O}_{2}, 80 \% \mathrm{CH}_{3} \mathrm{COOH} \\
\text { and } 70 \% \mathrm{HNO}_{3} \\
\text { Mechanical pre-treatment with homogenization }\end{array}$ & $5 \mathrm{~nm}$ wide & 81 \\
\hline Wheat straw & $\begin{array}{l}\text { Chemical treatment with } \mathrm{HCl} \\
\text { Mechanical treatment with cryocrushing and } \\
\text { homo-genization }\end{array}$ & $10-80 \mathrm{~nm}$ & 4 \\
\hline Soy hulls & $\begin{array}{l}\text { Chemical treatment with } \mathrm{HCl} \\
\text { Mechanical treatment with cryo-crushing and } \\
\text { homogenization }\end{array}$ & $20-120 \mathrm{~nm}$ & 4 \\
\hline $\begin{array}{l}\text { Sunflower stalks, coir fiber, } \\
\text { jute fiber }\end{array}$ & Steam explosion & $\begin{array}{l}\text { Diameters of sunflower stalks, coir fibers and jute } \\
\text { fibers are } 5-10 \mathrm{~nm}, 37.8 \mathrm{~nm} \text { and } 50 \mathrm{~nm} \text { respectively }\end{array}$ & $82-84$ \\
\hline Corn cob residue & TEMPO mediated oxidation and pulp refining & Diameter of almost $2.1 \mathrm{~nm}$, length $438 \mathrm{~nm}$ & 85 \\
\hline Banana fibers & $\begin{array}{l}\text { Steam explosion and acid treatment with } \mathrm{C}_{2} \mathrm{H}_{2} \mathrm{O}_{4} \\
\text { (oxalic acid) mechanical pretreatment with } \\
\text { mechanical stirring }\end{array}$ & Diameter $1 \mu \mathrm{m}$ & 86 and 87 \\
\hline Pine cones & Mechanical grinding & Diameter almost $15 \mathrm{~nm}$ & 88 \\
\hline Sisal fibers & Chemical treatment with acetic acid $\left(\mathrm{CH}_{3} \mathrm{COOH}\right)$ & Diameter $27 \pm 12 \mathrm{~nm}$, length $658 \pm 290 \mathrm{~nm}$ & 89 \\
\hline
\end{tabular}


Table 2 List of various sources of biopolymer nanocellulose, the isolation treatments used, the isolated CNPs and their dimensions

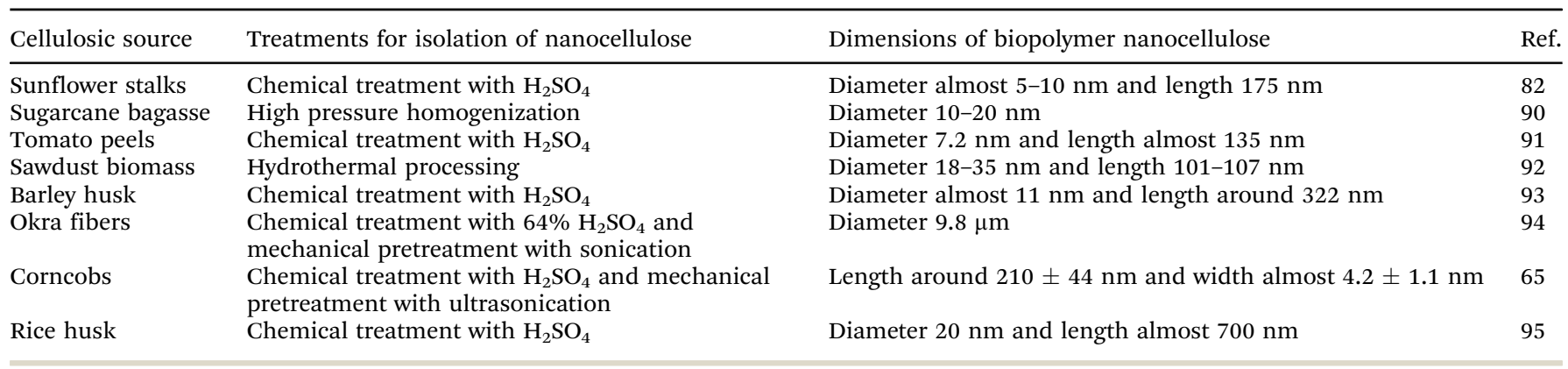

1.3.2. Enzymatic route of isolation. The enzymatic route for the pretreatment of bleached cellulose is used to obtain nanostructured cellulose. It is not possible to disintegrate cellulose via a single enzyme because it requires a set of cellulases $\left(\mathrm{C}_{18} \mathrm{H}_{32} \mathrm{O}_{16}\right)$ to disintegrate cellulose $\left(\left(\mathrm{C}_{6} \mathrm{H}_{10} \mathrm{O}_{5}\right)_{n}\right){ }^{29}$ Henriksson et al. demonstrated that the enzymatic cellobiohydrolases (CBHs) are further classified into type A- and B-cellulases $\left(\mathrm{C}_{18} \mathrm{H}_{32} \mathrm{O}_{16}\right)$ and are known as exoglucanases (EXG). ${ }^{121}$ These EXG promote the hydrolysis of crystalline cellulose at the end of the chain. Whereas Siro and Plackett reported that the other enzyme obtained is known as endoglucanase (EG) which promotes the degradation of amorphous cellulose..$^{29,58,122}$ Siqueira et al. reported the treatment of combined cellulases and hemicellulases as a synergistic effect to eliminate hemicelluloses and also promote the hydrolysis of cellulose. ${ }^{122}$ After the completion of the enzymatic treatment, the obtained MFCs show the most favorable structure, having a maximum aspect ratio. Campos et al. demonstrated the treatment of both hemicellulases or pectinase and EG to extract CNFs from curaua and sugarcane bagasse biomasses. ${ }^{123}$ The enzymatic pretreatment has major advantages, such as greater yields, it is environmentally friendly, has a larger selectivity, minimum energy costs and milder reaction conditions compared to other chemical processes. ${ }^{29,121}$ Pedersen and Meyer reported the major drawbacks of this route, that is the greater cost of enzymes, and the larger processing time required for the disintegration of cellulose. $^{124}$

1.3.3. Mechanical routes of isolation. Mechanical pretreatment isolation is used to generate fine fibers and involves various processes of isolation, such as high-pressure homogenization, sonication and cryocrushing methods. The highpressure homogenization technique involves the isolation of nanocellulose in an effective manner without treatment using toxic organic solvents. ${ }^{29,125-127}$ Nakagaito and Yano reported irreversible variations in the structure of the fiber owing to the alteration in the size and morphology. ${ }^{128} \mathrm{Li}$ et al. demonstrated the isolation of sugarcane bagasse via high-pressure homogenization pre-treatment. ${ }^{90}$ Another process for the isolation of nanocellulose is cryocrushing, in which fibers are treated with liquid nitrogen to obtain ice crystals which exert a larger pressure within the cell wall, which results in disintegration of the cell wall and the formation of CNFs. ${ }^{129}$ Alemdar and Sain used the cryocrushing process to isolate MFCs from wheat straw and soy hulls. ${ }^{4}$ Ultra-sonication pre-treatment is also one the most reliable and effective techniques for nanocellulose extraction and this proceeds via larger intensity ultrasonic waves, having a temperature and pressure greater than $5000{ }^{\circ} \mathrm{C}$ and
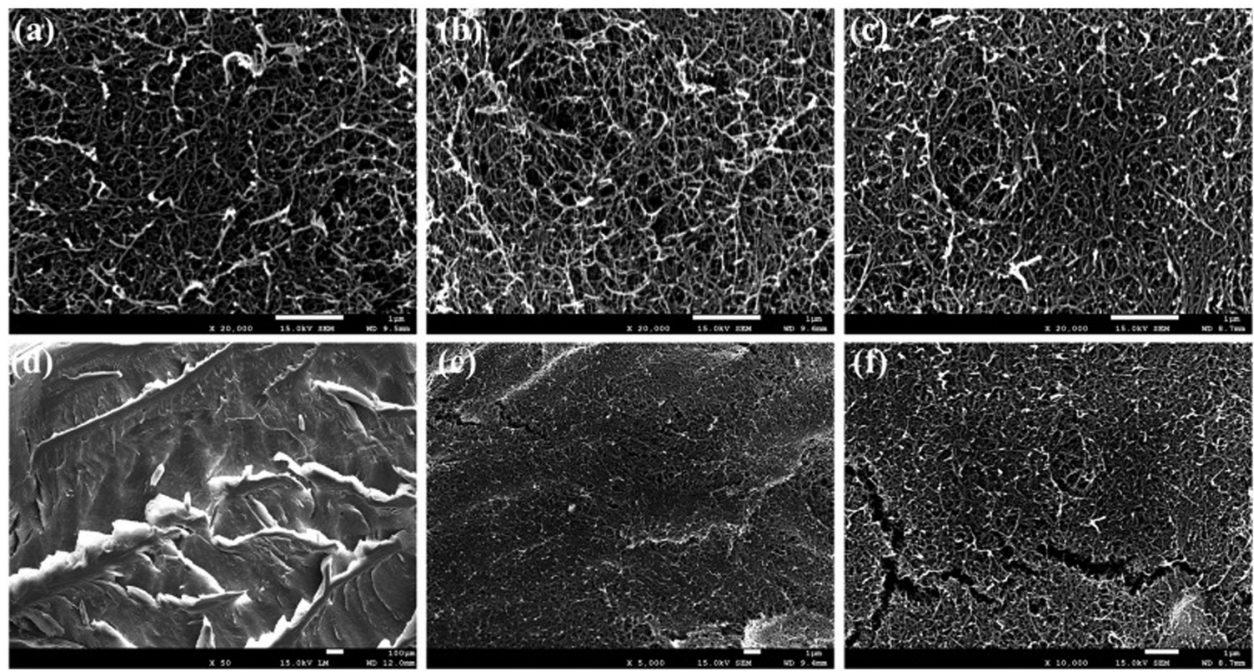

Fig. 7 SEM analysis of the morphology of the (a) 1.5-SCD-aerogel, (b) 2.5-SCD-aerogel, (c) 3.5-SCD-aerogel, (d) 1.5-SCD-aerogel, (e) 1.5-SCD-aerogel, and (f) 1.5-SCD-aerogel. Magnification: (a-c) $20000 x$; (d) 50x; (e) 5000x; and (f) $10000 \times$. Adapted with permission from ref. 120. Copyright 2016 Elsevier. 
500 atm respectively, resulting in effective fibrillation of the nanocellulose fibers. ${ }^{130}$ Wang and Cheng reported that the longer distance between the tip of the sonication probe and the cellulose suspension containing beaker is not favorable for the degradation of fibers from the cell wall. ${ }^{29,130}$ Sonication is generally performed after the chemical pre-treatment of natural raw fibers for nanocellulose isolation. ${ }^{30}$

1.3.4. Physicochemical routes of isolation. The physicochemical route is the combination of the chemical and mechanical approaches, in which the natural fibers are first pre-treated chemically and then mechanically via sonication or homogenization approaches. ${ }^{113,131}$ Wang and Sain reported the isolation of CNFs from a soybean source via chemo-mechanical treatment in which the cellulosic material initially proceeds via the chemical approach and then the mechanical (refining and beating) approach. ${ }^{129}$ Dufresne et al. demonstrated the isolation of MFCs from potato tubers by following a similar route in which chemical pre-treatment was used initially, followed by 15 passes of homogenization. ${ }^{132}$

\subsection{Different chemical routes for the surface functionalization of nanostructured cellulose}

Although, nanostructured cellulose is mostly hydrophilic in nature, it shows a non-continuous dispersion in several nonpolar solvents. The recent advances are focused on the surface functionalization of the nanostructured cellulose to maximize its compatibility and properties with various kinds of sources. Recently, researchers have adopted various modification treatments for the surface and structure of nanocellulosic materials (Scheme 1). ${ }^{67}$
The surface functionalization of cellulosic materials through chemical pre-treatments employs efficacious hydroxyl $(-\mathrm{OH})$ groups. ${ }^{29,30}$ The aim of this functionalization of nanostructured material is to improve its capacity for extraction and also to enhance the hydrophobicity on the surface, which results in maximum dispersibility and biocompatibility of the nanocellulosic materials in other solvents. ${ }^{133}$

1.4.1. Functionalization by imparting ionic surfaces to nanocellulosic material. The effective routes of functionalization that impart ionic surfaces are the phosphorylation route, carboxymethylation route, and oxidation and sulfonation routes, as shown in Scheme $1 .^{30}$ The extraction of nanostructured cellulose by pre-treatment using sulphuric $\left(\mathrm{H}_{2} \mathrm{SO}_{4}\right)$ and phosphoric acid $\left(\mathrm{H}_{3} \mathrm{PO}_{4}\right)$ leads to partial modification on the nanocellulosic surface providing the charges during isolation and the aqueous dispersion processes.

1.4.1.1. Functionalization through phosphorylation of the nanocellulosic material. The amalgamation of phosphate $\left(\mathrm{PO}_{4}{ }^{3-}\right)$ ester groups on the nanocellulosic surface results in enhancement of its original properties. Functionalization through phosphorylation of nanocellulose is an efficacious surface functionalization strategy for generating supreme materials for advances in diverse fields such as orthopedics, ${ }^{134}$ textiles, ${ }^{135}$ biomedical sciences, ${ }^{136}$ soil and dye adsorption, ${ }^{137}$ fuel cells, ${ }^{138}$ wastewater treatments, ${ }^{139}$ biochemical segregations, and ion interchange efficiency. ${ }^{140}$ Modified nanocellulose is more biocompatible with $\mathrm{Ca}\left(\mathrm{PO}_{4}\right)_{2}$ (calcium phosphate), which leads to the formation of a hybrid structure. Nanocellulosic materials have a more flammable nature and reduced thermal stability.

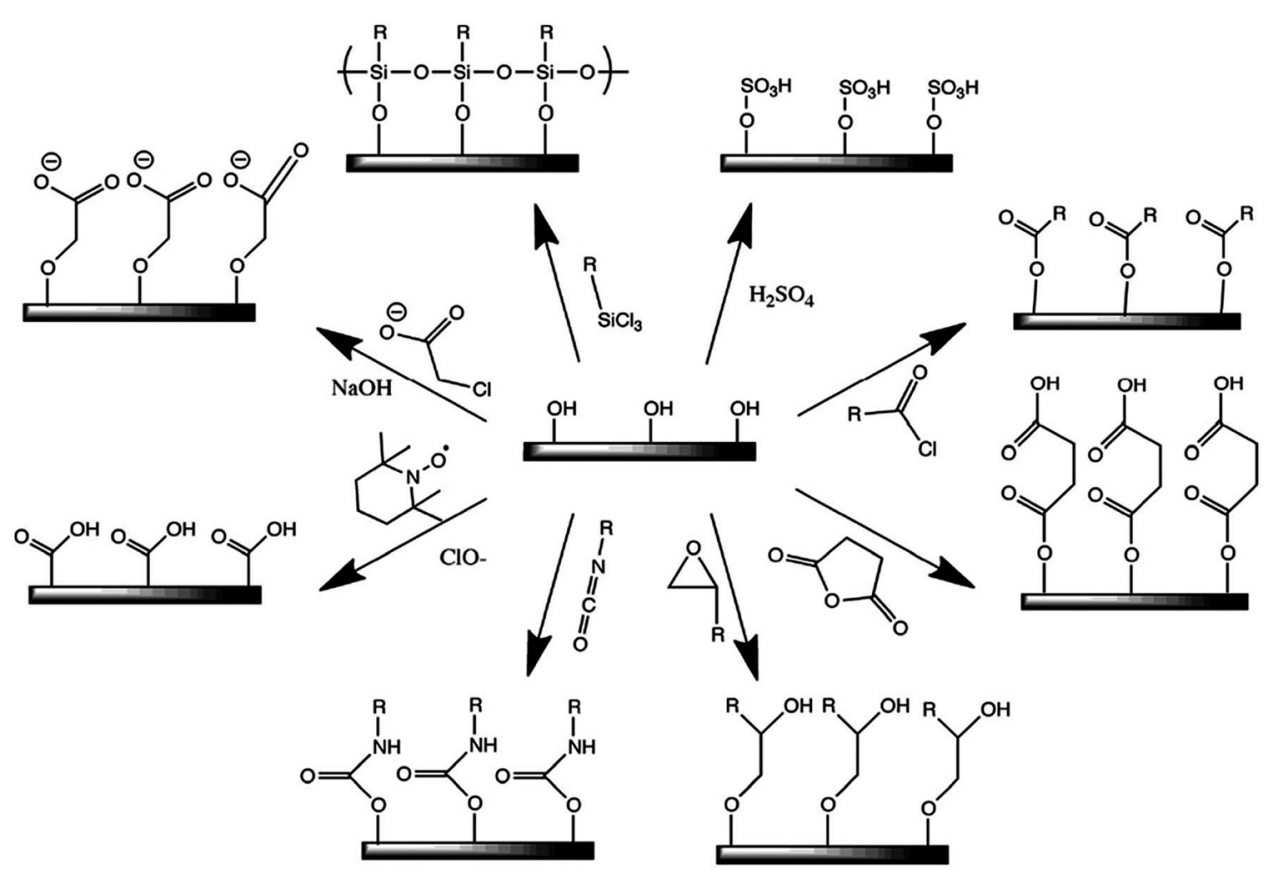

Scheme 1 Some common surface modifications of nanocellulose: (clockwise from top-right) sulfuric acid treatment provides sulfate esters, carboxylic acid halides create ester linkages, acid anhydrides create ester linkages, epoxides create ether linkages, isocyanates create urethane linkages, TEMPO mediated hypochlorite oxidation creates carboxylic acids, halogenated acetic acids create carboxymethyl surfaces, and chlorosilanes create an oligomeric silylated layer. Adapted with permission from ref. 67. Copyright 2019 Royal Society of Chemistry. 
The crystalline form of the nanocellulosic material is thermally more stable, although the amorphous parts in the cellulosic material are highly reactive towards combustion. The modification through an inorganic ester on cellulose based nanocrystals provides phosphate and sulfate esters which liberate the phosphoric and sulphuric acids, favoring the dehydration process and generation of char. ${ }^{141,142}$ The corresponding sulphuric acid and phosphate esters catalyze the dehydration of nanocellulose to provide $\mathrm{C}=\mathrm{C}$ stable bonds that lead towards flame retardation. ${ }^{30,143,144}$ The resultant functionalized phosphorylated nanocellulosic polymer could be applied to other polymeric chains to enhance its properties and can be used for large scale applications. Various agents are adopted in the functionalization of nanocellulose, such as $\mathrm{POCl}_{3}$ (phosphorus oxychloride), $\mathrm{P}_{2} \mathrm{O}_{5}$ (phosphorus pentoxide), $\left(\mathrm{NH}_{4}\right)_{2} \mathrm{HPO}_{4}$ (diammonium hydrogen phosphate), ${ }^{145} \mathrm{H}_{3} \mathrm{PO}_{4}$ (phosphoric acid) ${ }^{146}$ and organophosphates.

1.4.1.2. Functionalization of nanocellulosic materials through carboxymethylation. Surface functionalization of nanocellulosic material occurs through the carboxymethyl $\left(-\mathrm{CH}_{2}-\mathrm{COOH}\right)$ groups via the carboxymethylation process that enhances the negative charge on the surface of the material. The negative charges on the nanocellulosic surface involve electrostatic repulsions and also enhance the degradation of materials into nanosized particles. ${ }^{30,147}$ Wagberg et al. built-up a nanofibrillated cellulosic surface to a diameter of 5-15 nm by providing carboxymethylated groups. ${ }^{148}$ Siró et al. functionalized the surface of softwood pulp through carboxymethylated groups $\left(-\mathrm{CH}_{2}-\mathrm{COOH}\right)$ by using homogenization steps, the optimized carboxymethylated nano-fibrillated cellulosic gels could probably form oxygen barriers that have transparent films. ${ }^{149}$

1.4.1.3. Functionalization through the oxidation method. Functionalization through the oxidation of nanocellulosic material can be performed using TEMPO (2,2,6,6-tetramethylpiperidine-1-oxyl) mediated oxidation mechanism (Fig. 8$)^{30,150}$ to provide the hydrophobic nanocellulosic surface. ${ }^{151}$ De Nooy et al. first demonstrated this method and reported that TEMPO mediated oxidation can probably oxidize the primary alcohols, for example the hydroxymethyl $\left(-\mathrm{CH}_{2}-\mathrm{OH}\right)$ groups of the polysaccharides with unaffected secondary hydroxyl $(-\mathrm{OH})$ groups. ${ }^{152}$ This method involves the conversion of exposed $\mathrm{C} 6$ alcoholic group based functions of the $\mathrm{C}_{6} \mathrm{H}_{12} \mathrm{O}_{6}$ (glucose) unit into carboxylic acid $(-\mathrm{COOH})$ and also stable nitroxyl radicals converted the hydroxyl groups $(-\mathrm{OH})$ into aldehydes, then these were further oxidized into carboxylic acids. ${ }^{153,154}$ Araki et al. demonstrated the hydrolyzation of $\mathrm{HCl}$ followed by the TEMPO-mediated oxidation of the cellulose nanocrystals. ${ }^{155}$

1.4.1.4. Functionalization of nanocellulose through the sulfonation method. The functionalization of nanocellulosic materials through the sulfonation technique is also used to impart anionic charges to the nanocellulosic surface. Isolation of CNCs involves treatment with concentrated $\mathrm{H}_{2} \mathrm{SO}_{4}$ (sulfuric acid) and in this process sulfate half-esters are formed from the hydroxyl groups of the CNVs that lead to hydrolysis of sulfuric acid having stable colloidal suspensions of CNCs. ${ }^{30,156,157}$ This process shows phase segregation into a chiral nematic phase in a particular concentration range. The surface possesses sulfate groups with a negative charge that form a negative electrostatic layer and improves the dispersion efficiency in water. However, the thermal stability of the $\mathrm{H}_{2} \mathrm{SO}_{4}$ isolated nanocellulosic material can be enhanced by the neutralization process using $\mathrm{NaOH} .^{76,158}$ During hydrolysis with $\mathrm{H}_{2} \mathrm{SO}_{4}$ and $\mathrm{HCl}$, spherical cellulose nanocrystals are generated through the sonication process, having low density based sulfate groups with a maximum thermal stability, as compared to the hydrolysis of pure $\mathrm{H}_{2} \mathrm{SO}_{4} \cdot{ }^{30}$ Liimatainen et al. added $\mathrm{NaIO}_{4}$ (periodate) and $\mathrm{NaHSO}_{3}$ (bisulfite) to nano-fibrillated hardwood pulp that led to the generation of sulfonated based NFCs having a diameter range between $10-60 \mathrm{~nm}^{159}$

1.4.2. Functionalization resulting from the generation of hydrophobic surfaces on nanocellulosic materials. The methods

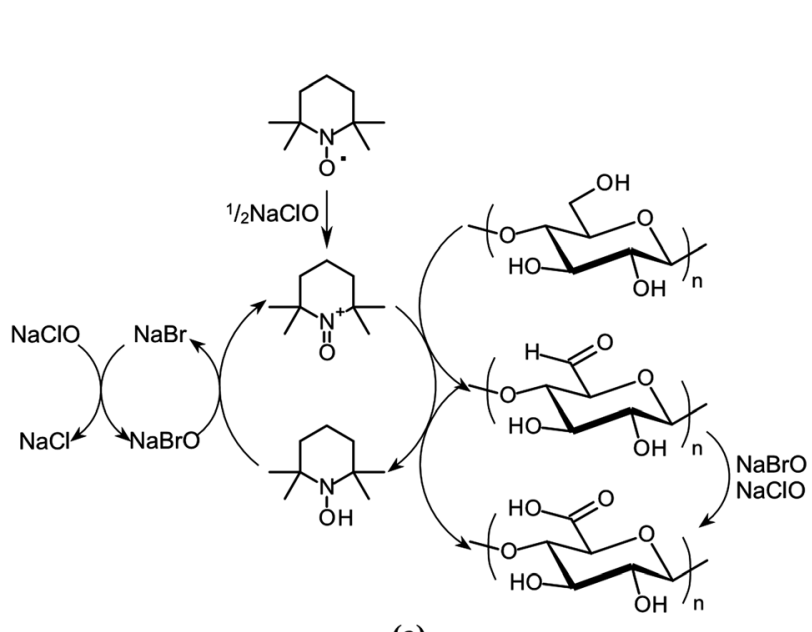

(a)

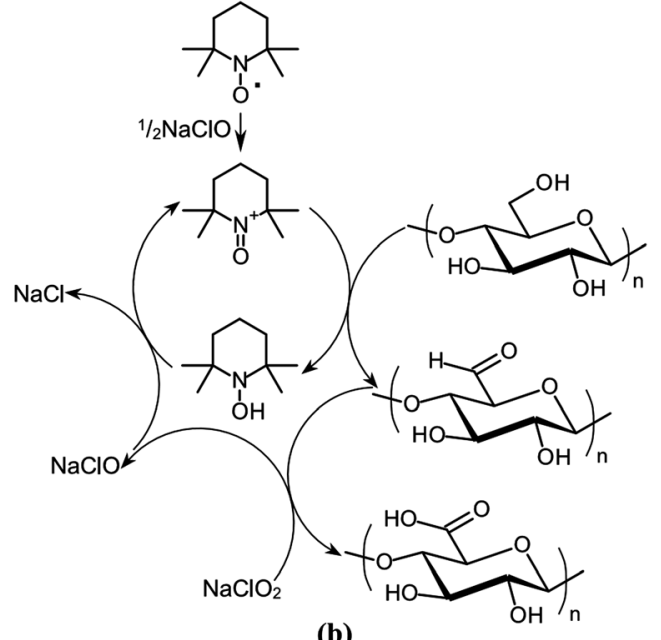

(b)

Fig. 8 Schematic diagram of the regioselective oxidation of cellulose primary alcohol groups by: (a) TEMPO/NaBr/NaClO in water at basic pH and (b) TEMPO/NaClO/NaClO 2 in water at neutral or slightly acidic pH. Adapted with permission from ref. 150. Copyright 2016 Elsevier. 


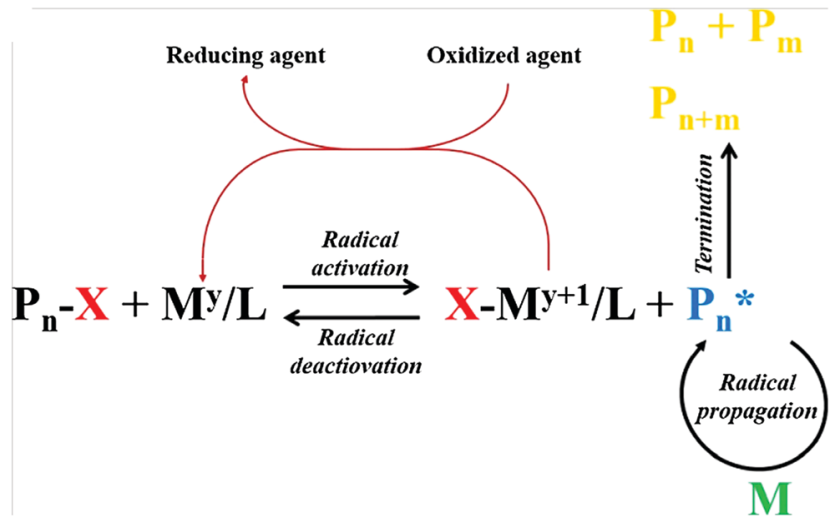

Scheme 2 General steps of the ARGET ATRP mechanism. Adapted with permission from ref. 198. Copyright 2019 Elsevier.

of surface functionalization for generating hydrophobic surfaces include esterification, amidation, silylation, urethanization, and etherification methods and they lead to a change in the sensitivity of nanocellulose towards the moisture content and hydrophobic surface. Owing to the hydrophilic nature of the nanocellulosic material it absorbs water upon exposure. ${ }^{30}$ The aim for these chemical functionalization techniques is to change only the surface of the nanocellulose, maintaining the complex composition of the hydroxyl $(-\mathrm{OH})$ groups and the initial morphology. ${ }^{160}$ The effective routes for functionalization for generating hydrophobic surfaces on nanocellulosic materials are shown in Scheme $2 .^{30}$

1.4.2.1. Functionalization on a nanocellulosic surface through acetylation. Functionalization of nanocellulose is also performed to enhance its hydrophobicity through the acetylation method. This method of acetylation usually involves the addition of $\mathrm{C}_{4} \mathrm{H}_{6} \mathrm{O}_{3}$ (acetic anhydride) and dry $\mathrm{CH}_{3} \mathrm{COOH}$ (acetic acid) with either $\mathrm{H}_{2} \mathrm{SO}_{4}$ or $\mathrm{HClO}_{4}$ (perchloric acid) for catalyzation during the reaction. ${ }^{30,161-163}$ Sassi et al. first proposed the two main mechanisms involved in the acetylation process, that is the homogeneous and fibrous process in the presence or absence of a swelling diluent. ${ }^{164}$ During the fibrous process, a diluent such as toluene is used and when it is added to the reaction mixture the resultant acetylated cellulosic material remains insoluble and a high degree of acetylation is obtained, during which the original morphology is maintained. On the other hand, the diluent-free homogeneous method involves soluble acetylated chains with $\mathrm{CH}_{3} \mathrm{COOH}$ and a catalytic amount of $\mathrm{H}_{2} \mathrm{SO}_{4}$. Çetin et al. reported the acetylation of cellulosic nano-whiskers through $\mathrm{C}_{4} \mathrm{H}_{6} \mathrm{O}_{2}$ (vinyl acetate) under modest conditions in which only the surface of the nanocrystal was functionalized, whereas the crystallinity and original dimensions of the material were preserved. ${ }^{165}$ During this process the degree and rate of acetylation were examined through diffusion. After a prolonged reaction time, the reported nanocrystals have a smaller size, lower percentage of crystallinity and the maximum amount of acetylation.

1.4.2.2. Functionalization of nanocellulose through etherification. The process of functionalization of the nanocellulosic material through etherification occurs through carboxymethylation of nanocellulose, the initial step of this process is to activate the fibers using aqueous $\mathrm{NaOH}$, which acts as an alkali hydroxide, and the second step is to convert the hydroxyl $(-\mathrm{OH})$ groups to carboxymethyl $\left(-\mathrm{CH}_{2}-\mathrm{COOH}\right)$ moieties with $\mathrm{C}_{2} \mathrm{H}_{3} \mathrm{ClO}_{2}$ (monochloroacetic acid), or its sodium salt. ${ }^{30}$ Eyholzer et al. reported the dispersion and capability of the carboxymethylated NFCs powder functionalized with 1-hexanol $\left(\mathrm{C}_{6} \mathrm{H}_{14} \mathrm{O}\right)$ in extruded PLA (poly(lactic acid)) composites. ${ }^{166}$ Hasani et al. demonstrated the grafted cationic surface modification of CNCs through the etherification process. In this process, alkali-activated hydroxyl $(-\mathrm{OH})$ moieties of the cellulose backbone reacted through nucleophilic addition to the epoxide of epoxypropyl-trimethylammonium chloride (EPTMAC) resulting in stable aqueous suspensions having thixotropic gelling properties. ${ }^{167}$

1.4.2.3. Functionalization of nanocellulose through the silylation method. The functionalization of the nanocellulosic material through the silylation method involves silane surface functionalization which is a simple route to enhance the hydrophobicity of the hydrophilic cellulosic surface, alkyl-dimethylchlorosilanes are widely used in the silylation process. ${ }^{26}$ Goussé et al. proposed the rheological properties of MFCs after moderate silylation using $\mathrm{C}_{3} \mathrm{H}_{8} \mathrm{O}$ (isopropyl) $\left(\mathrm{CH}_{3}\right)_{2} \mathrm{SiHCl}$ (dimethylchlorosilane). These silylated MFCs showed a supreme flexibility and rheological properties during suspension in $\mathrm{C}_{19} \mathrm{H}_{36} \mathrm{O}_{2}$ (methyl oleate), providing a shear thinning effect. ${ }^{168}$ Andresen and his coworkers successfully reported the functionalization of chlorodimethyl isopropyl-silane to silylate on the surface of the MFCs. ${ }^{169}$ The morphological integrity at mild degrees of substitution also helps to stabilize the water-in-oil emulsions during modification of the MFCs. Zhang and his co-workers recently demonstrated the applications of supreme flexibility based silylated nanocellulosic material sponges to eliminate oil from water. ${ }^{170}$

1.4.2.4. Functionalization of nanocellulose through urethanization. The process of functionalization through the urethanization method involves the reaction between isocyanate $(\mathrm{R}-\mathrm{N}=\mathrm{C}=\mathrm{O})$ and hydroxyl $(-\mathrm{OH})$ groups of nanocellulose and results in the formation of covalent bonds. ${ }^{30,133}$ Siqueira et al. reported the surface functionalization of CNCs and MFCs through $n$-octadecyl isocyanate $\left(\mathrm{C}_{19} \mathrm{H}_{37} \mathrm{NO}\right)$, which enhances the hydrophobicity of nanocellulose. The degree of substitution values for modification through isocyanate grafting were 0.07 and 0.09 for CNCs and NFCs, respectively. ${ }^{171}$ Recently, Biyani and his co-workers reported the isocyanate-mediated coupling to $\mathrm{CNCs}$ with $\mathrm{H}$-bonded ureidopyrimidione $\left(\mathrm{C}_{5} \mathrm{H}_{6} \mathrm{~N}_{4} \mathrm{O}_{2}\right){ }^{172}$

\subsubsection{Functionalization of nanocellulose through amidation.} The process of functionalization by using amidation is the most common route used to amidate cellulosic surfaces through a carbodiimide-mediated reaction. This process probably targets the carboxylic groups $(-\mathrm{COOH})$ of preoxidized nanocellulosic substrates. The most widely used carbodiimide for the nanocellulosic amidation reaction is EDAC $\left(\mathrm{C}_{8} \mathrm{H}_{17} \mathrm{~N}_{3}\right)$ or $N$-ethyl- $N$ (3-(dimethylamino)-propyl)carbodiimide hydrochloride which 
Table 3 Various studies based on applications and modification routes of nanocellulosic materials

\begin{tabular}{|c|c|c|c|}
\hline S. no. & $\begin{array}{l}\text { Various studies based on applications of nanocellulosic } \\
\text { materials }\end{array}$ & $\begin{array}{l}\text { Method used for the modification } \\
\text { of nanocellulose }\end{array}$ & Ref. \\
\hline 1. & $\begin{array}{l}\text { Applications of functionalized acetylated nanofibrillated } \\
\text { cellulosic material that act as a toughening material or } \\
\text { agent in poly(lactic acid). } \\
\text { The aim of this study is to functionalize the nanocellulosic } \\
\text { whisker using vinyl acetate under mild conditions. }\end{array}$ & Acetylation method & 163 and 165 \\
\hline 2. & $\begin{array}{l}\text { Applications of cyclodextrin nanocellulose functionalized } \\
\text { through the amidation process for the detection of the } \\
\text { antibiotic danofloxacin in milk. }\end{array}$ & Amidation method & 173 \\
\hline 3. & $\begin{array}{l}\text { Applications of functionalized carboxymethylated } \\
\text { nanofibrillated cellulose, and their properties and effects on } \\
\text { various homogenization stages. }\end{array}$ & Carboxymethylation method & 149 and 166 \\
\hline 4. & $\begin{array}{l}\text { This study focused on modification of nanofibrillated } \\
\text { cellulosic materials through the surface silylation method } \\
\text { and their rheological characteristics. } \\
\text { Applications of silylated nanocellulosic materials having an } \\
\text { ultralight weight and supreme flexibility for the } \\
\text { elimination of oil from water. }\end{array}$ & Silylation method & 168 and 170 \\
\hline 5. & $\begin{array}{l}\text { Applications of modified sulfonated cellulosic nanocrystals } \\
\text { for supreme dispersive micro solid phase isolation and } \\
\text { detection of Ag-nanoparticles in food items. }\end{array}$ & Sulfonation method & 30 and 68 \\
\hline 6. & $\begin{array}{l}\text { The aim of this study is to explain the behavior or } \\
\text { rheological properties of a nanofibrillated cellulosic } \\
\text { suspension of pulp through TEMPO mediated oxidation. }\end{array}$ & $\begin{array}{l}\text { TEMPO-mediated oxidation } \\
\text { method }\end{array}$ & 152 \\
\hline 7. & $\begin{array}{l}\text { Applications of modified cellulosic nanomaterials that act } \\
\text { as a light healable supramolecular nanomaterial. }\end{array}$ & Ureathanization method & 172 \\
\hline 8. & $\begin{array}{l}\text { Modified bacterial nanocomposites for applications based } \\
\text { on the sorption of proteins. } \\
\text { Modified phosphorylated nanocellulose derivatives for } \\
\text { the sorption of metal ions such as } \mathrm{Ag}^{+}, \mathrm{Cu}^{2+}, \mathrm{Fe}^{3+} \text { from } \\
\text { industrial wastes. } \\
\text { Modified phosphorylated CNCs used as a renewable } \\
\text { nano-cellulosic material for the generation of flame } \\
\text { retardant materials. } \\
\text { Modified phosphorylated nanocellulosic materials based } \\
\text { on a propionate derivative act as a thermoplastic flame } \\
\text { retardant material and it also explains the effect of } \\
\text { phosphorylation on thermal degradation. }\end{array}$ & Phosphorylation method & $136,139,140$ and 146 \\
\hline
\end{tabular}

has a $\mathrm{pH}$ range between $7-10 .^{30}$ Ruiz-Palomero and his coworkers demonstrated the covalently bonded $\beta$-cyclodextrin $\left(\left(\mathrm{C}_{6} \mathrm{H}_{10} \mathrm{O}_{5}\right)_{2}\right)$ to the amine functionalized nanocellulosic material via an amidation reaction that is an applicable danofloxacin $\left(\mathrm{C}_{19} \mathrm{H}_{20} \mathrm{FN}_{3} \mathrm{O}_{3}\right)$ sorbent in the critical fluorimetric determination of this medicine in milk. ${ }^{173}$ Studies based on various applications and modification routes are studied in this review, as shown in Table 3.

1.4.3. Functionalization through polymer grafting on cellulosic material. Modification of nanocellulosic material through the grafting route is one of the best methods used to enhance the physical and chemical properties of polymeric materials. ${ }^{174,175}$ Nanocellulose composites have been isolated to improve the hydrophilicity or hydrophobicity on cellulosic surfaces having more elasticity, thermal resistance, ion exchange properties, stability and sorbent properties. ${ }^{176}$ Grafted nanocellulosic materials have been used for surgical repair applications owing to their supreme mechanical and biocompatible properties with reduced degradability. ${ }^{33,141-145}$ Grafting of polymers involves three routes of modification, these are the grafting from, grafting to, grafting through routes (Fig. 3). ${ }^{8}$ The "grafting-to" route involves well-characterized and purified polymers which are linked to the cellulosic material through coupling of the polymeric active end groups to the hydroxyl $(-\mathrm{OH})$ groups of the cellulosic backbone, polymers such as polypropylene $\left(\left(\mathrm{C}_{3} \mathrm{H}_{6}\right)_{n}\right)$, polystyrene $\left(\left(\mathrm{C}_{8} \mathrm{H}_{8}\right)_{n}\right)$, poly(lactic acid) $\left(\left(\mathrm{C}_{3} \mathrm{H}_{4} \mathrm{O}_{2}\right)_{n}\right)$, poly-(caprolactone) $\left(\left(\mathrm{C}_{6} \mathrm{H}_{10} \mathrm{O}_{2}\right)_{n}\right)$ and so on, can be obtained and linked to the backbone of cellulose. Whereas the "grafting-from" route involves the functionalization of cellulose through an initiator and monomers are also polymerized directly through the surface, having greater polymer densities and polydispersity than the grafting-to route, but there are difficulties in the characterization of the resulting polymers. On the other hand, the "grafting-through" route involves the functionalization of cellulosic material through polymerizable species, that is vinyl based monomers, after that this modified cellulosic material is mixed with a co-monomer and then the polymerization reaction is initiated..$^{8,30,178,179}$ Out of all the routes of grafting, "grafting-from" is the best and most effective method which also involves ROP, ${ }^{5,180}$ stabilization of colloidal functionalized nanocellulose and the radical polymerization grafting routes. The grafting-to route involves many approaches, such as the free radical, ATRP, ROP and RAFT which are explained in this section. Various studies on modification through grafting are presented in Table $4 .{ }^{8,78,111,123,126,181-191}$ 
Table 4 Different reported studies on cellulose grafting via various polymer matrixes or grafting agents

\begin{tabular}{|c|c|c|c|c|}
\hline S. no. & Source of biopolymer cellulose & $\begin{array}{l}\text { Nanocellulosic form of } \\
\text { cellulose composite } \\
\text { (if any) }\end{array}$ & Surface functionalized polymer matrix & Ref. \\
\hline 1. & Wood pulp & CNFs & $10 \mathrm{wt} \%$ PVA (polyvinyl alcohol) and $5 \mathrm{wt} \%$ PLA & 181 \\
\hline 2. & Sugarcane bagasse & - & EDTA dianhydride $\left(\mathrm{C}_{10} \mathrm{H}_{12} \mathrm{~N}_{2} \mathrm{O}_{6}\right)$ & 8,123 and 182 \\
\hline 3. & Cotton & CNCs & $0-12$ wt $\%$ PVA & 183 \\
\hline 4. & Tunicate & CNCs & $\begin{array}{l}6 \mathrm{wt} \% \text { styrene/butyl acrylate, } 25 \mathrm{wt} \% \text { starch and } \\
0.5-5 \mathrm{wt} \% \text { waterborne epoxy }\end{array}$ & $184-187$ \\
\hline 5. & Flax fibers & CNFs & $0-30 \mathrm{wt} \%$ waterborne polyurethanes and $10 \mathrm{wt} \%$ PVA & 181 and 188 \\
\hline 6. & Saw dust & - & Acrylic acid as a polymer matrix & 8 and 189 \\
\hline 7. & Cellulosic okra waste & CNFs & Glycidyl methacrylate & 78, 111 and 179 \\
\hline 8. & Potato pulp & CNFs & $0-40$ wt\% starch/glycerol & 190 \\
\hline 9. & Soyhull and wheat straw & CNFs & No functionalization was made with nanocomposites & 126 \\
\hline 10. & Banana fibers & CNFs & Acrylonitrile $\left(\mathrm{C}_{3} \mathrm{H}_{3} \mathrm{~N}\right)$ & 191 \\
\hline
\end{tabular}

1.4.3.1. Atom-transfer radical polymerization route of grafting. The ATRP route for the grating of biopolymer nanocellulose is followed by the free radical polymerization process applied to styrenes $\left(\mathrm{C}_{8} \mathrm{H}_{8}\right)$, methyl-acrylates $\left(\mathrm{C}_{4} \mathrm{H}_{6} \mathrm{O}_{2}\right)$, (meth)acrylamides $\left(\mathrm{C}_{4} \mathrm{H}_{7} \mathrm{NO}\right)$, and acrylonitriles $\left(\mathrm{C}_{3} \mathrm{H}_{3} \mathrm{~N}\right) .^{30,192}$ The ATRP approach was initially reported in 2002, in which a reaction is carried out between the surface hydroxyl $(-\mathrm{OH})$ groups and 2-bromoisobutyryl bromide $\left(\mathrm{C}_{4} \mathrm{H}_{6} \mathrm{Br}_{2} \mathrm{O}\right)$ which acts as an initiator in the ATRP polymerization of $\mathrm{C}_{4} \mathrm{H}_{6} \mathrm{O}_{2}$ (methyl acrylate) ${ }^{193}$ CNCs have been modified via grafting with PMA (poly(methyl acrylate)) to generate materials dispersible in tetrahydrofuran $\left(\mathrm{C}_{4} \mathrm{H}_{8} \mathrm{O}\right)$, chloroform $\left(\mathrm{CHCl}_{3}\right)$, DMF (dimethylformamide), and DMSO (dimethyl sulfoxide), in contrast to the unmodified CNCs. The ATRP grafting route has been well established and research in this field is now turning towards large scale industrial applications. The ATRP process involves the grafting of hydrophobic PMA onto a variety of different cellulosic surfaces. ${ }^{194-196}$ The process of atom transfer radical polymerization can also be catalyzed through a redox mechanism via transition metal complexes, ${ }^{197}$ as shown in Scheme $2^{198}$ followed by atomic transfer radical addition.

1.4.3.2. Reversible addition fragmentation chain transfer route of grafting. The RAFT approach of grafting is another grafting-to route approach used for the same set of monomers, vinyl esters and also for vinyl amides. RAFT has major advantages because the end group can be effortlessly reduced into a thiol, providing more effective functional groups that can be further modified as shown in Scheme $3 .{ }^{199-202}$ The RAFT approach is also used to obtain soluble cellulose using polymerizing acrylic monomers and to generate a RAFT agent (macro chain transfer agent) by attaching dithioesters to the primary alcohol $\left(-\mathrm{CH}_{2} \mathrm{OH}\right)$ at the C6 position on the cellulosic backbone by polymerizing either the ethyl acrylate $\left(\mathrm{C}_{5} \mathrm{H}_{8} \mathrm{O}_{2}\right)$ or NIPAM ( $N$-isopropylacrylamide). Poly(2-(dimethylamino)ethyl methacrylate) or p-DMAEMA $\left(\mathrm{C}_{8} \mathrm{H}_{15} \mathrm{NO}_{2}\right)$ is modified via grafting on the cellulosic surface using the RAFT approach. ${ }^{30,202,203}$

1.4.3.3. Free radical grafting route of functionalization. Cellulose nanocrystals were included in temperature-responsive poly $(\mathrm{N}$ isopropylacrylamide) or p-NIPAM $\left(\mathrm{C}_{6} \mathrm{H}_{11} \mathrm{NO}\right)_{n}$ cryogels by using a free radical polymerization route. Both physically adsorbed and covalently bound celluloses were obtained through modification of the surface with polymerizable species and it was reported that physically adsorbed CNCs were more hydrophilic, which are responsible for the homogeneously incorporated maximum loading capabilities. Whereas the covalently bounded CNCs produced gels reporting a maximum diffusion owing to properties such as the larger degree of swelling and the porous structure of the material. ${ }^{179,204,205}$ Above the lower critical solution temperature (LCST) or $32{ }^{\circ} \mathrm{C}$ for the polymer, the obtained gel was reversibly reduced. The combination of CNCs with the gel allowed it to retrieve its form after compression, as compared to the pure polyacrylamide $\left(\left(\mathrm{C}_{3} \mathrm{H}_{5} \mathrm{NO}\right)_{n}\right)$ gels. ${ }^{30}$ During free radical polymerization, benzyloxy and phenyl free radicals are used to initiate the

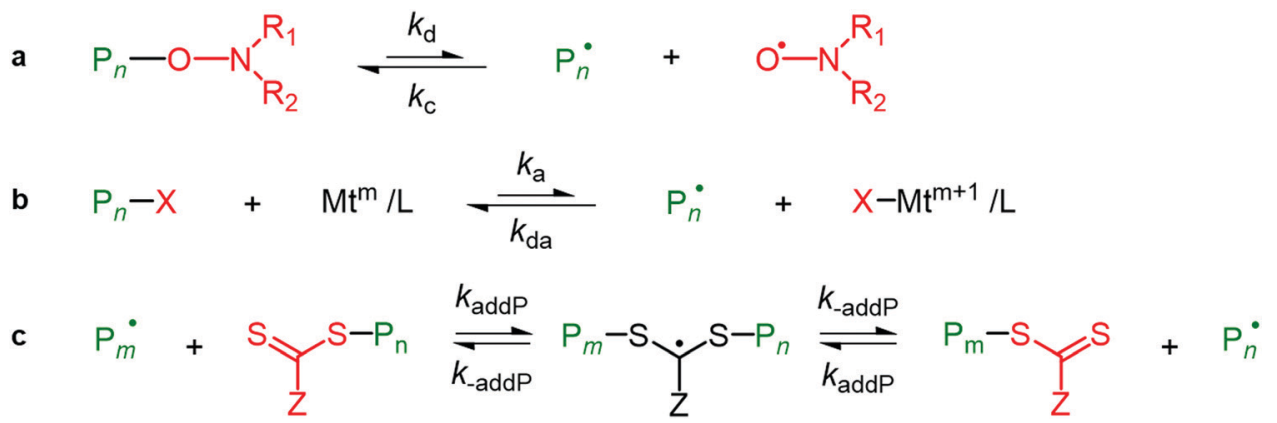

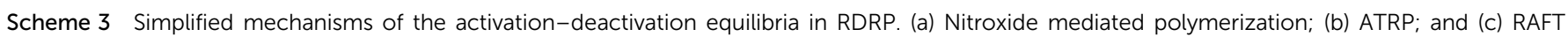
polymerization. Adapted with permission from ref. 199. Copyright 2020 Elsevier. 


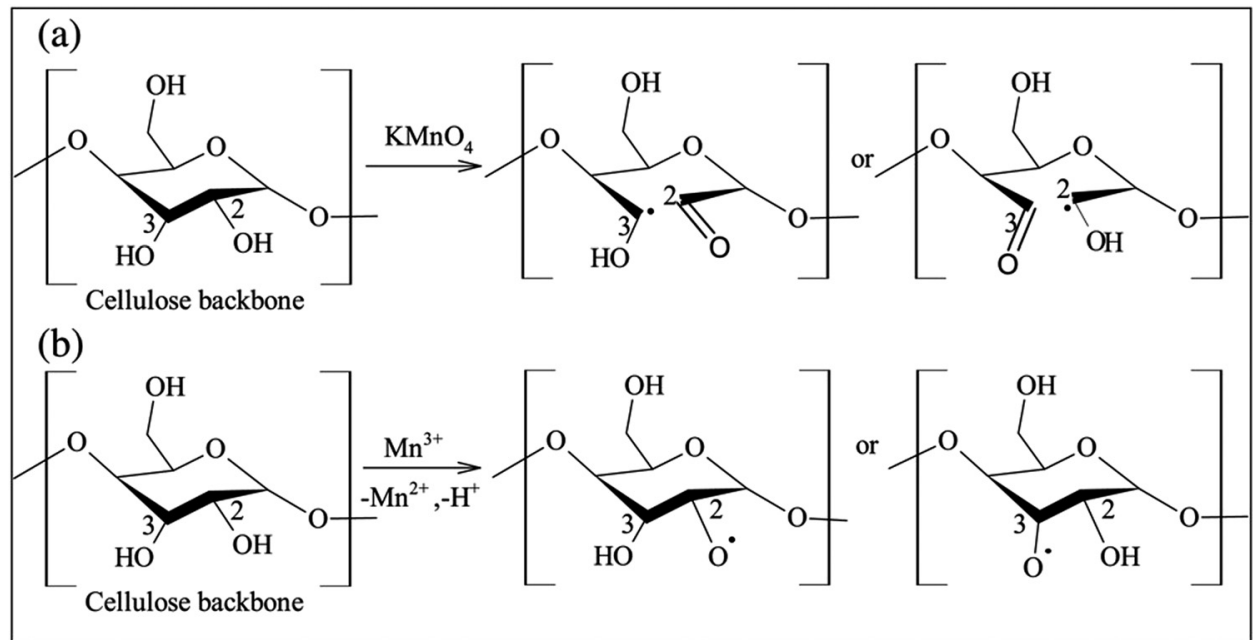

Scheme 4 Different proposed mechanisms for free radical grafting of cellulose initiated by $\mathrm{KMnO}_{4}$. Adapted with permission from ref. 5. Copyright 2017 Elsevier.

mechanism of polymerization in which the stabilized phenyl free radical is formed from the unstable benzyloxy radical and $\mathrm{CO}_{2}$ is liberated (Scheme 4). ${ }^{5,8}$

1.4.3.4. Ring opening polymerization route of grafting. The ROP route of grafting is applied to cyclic monomers, for example lactones, epoxides and lactams and can be carried out via radicals such as anionic or cationic initiators, through anionic and cationic ring opening (AROP and CROP) mechanisms, the obtained ring is considered for the generation of mechanically stable and biocompatible polymeric materials, as shown in Scheme 5. ${ }^{180,206-208} \mathrm{Li}$ et al. demonstrated the grafted stable, effective and biocompatible nanocomposite polymer from cellulosic fibers by using ROP for the applications, such as tissue repair engineering, biomedical implants and so on. ${ }^{208}$ The cellulosic backbone with reactive hydroxyl groups was activated with tin(II) 2-ethylhexanoate ( $\mathrm{Sn}(\mathrm{Oct}) 2)$ and then applied to open L-lactide $\left(\mathrm{C}_{6} \mathrm{H}_{8} \mathrm{O}_{4}\right)$ and $\varepsilon$-caprolactone $\left(\mathrm{C}_{6} \mathrm{H}_{10} \mathrm{O}_{2}\right)$ monomers. ${ }^{207}$

1.4.3.5. Post-polymerization route of grafting. The postpolymerization route of the grafting-from approach involves grafting from polystyrene $\left(\mathrm{C}_{8} \mathrm{H}_{8}\right)_{n}$ and poly(tert-butyl acrylate) $\left(\left[\mathrm{C}_{8} \mathrm{H}_{14} \mathrm{O}_{2}\right]_{n}\right)$ onto oxidized CNCs via the amidation reaction which couples the terminal amines onto polymers with the carboxylic acid $(-\mathrm{COOH})$ groups of the cellulosic material, which has a grafting density of around 60-64 wt\%, this is sufficient to solubilize the nanocomposite into acetone and toluene. This grating-from polymerization route could be used for a large variety of polymers with no degradation of CNCs using the modification method. ${ }^{30,209}$

\subsection{Effect of surface modification on various properties of nanocellulose}

With the decreasing size of a cellulosic biopolymer from the microscale, such as for polymeric materials, to the nanoscale, such as for cellulosic nanomaterials, various parameters change and these lead to more effective and novel applications. ${ }^{23,27}$ These modifications provide potential nanomaterials which can be used as reinforcing agents in various nanocomposites and also promotes the specific features for the production of novel cellulosic nanomaterials, with the objective of promoting its applications in the field of modified nanomaterials. The major properties that are influenced by surface modification of cellulosic nanomaterial are reported below.

1.5.1. Effect of modification on the crystallinity of nanocellulose. The crystallinity of modified nanocellulose mainly depends on the lignocellulosic source. Many studies have revealed

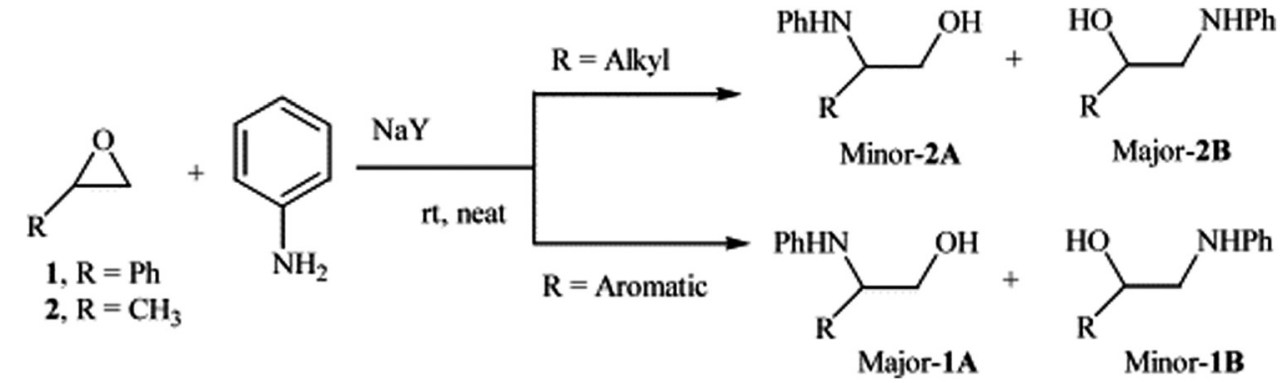

Scheme 5 Ring opening polymerization of epoxides using aliphatic and aromatic amines. Adapted with permission from ref. 206 . Copyright 2006 Elsevier. 
that the cellulosic nanocrystal obtained from $\mathrm{H}_{2} \mathrm{SO}_{4}$ exhibits lower crystalline values in contrast to that obtained from $\mathrm{HCl}^{14,210}$ Another factor which influences the crystallinity value is the time period of hydrolysis, a greater hydrolysis time period results in the removal or disintegration of the amorphous phase and enhances its crystallinity value. The crystallinity values of the cellulosic content for these samples follows the sequence pineapple $>$ banana $>$ jute. For example, the values for the degree of crystallinity of nanocrystal cellulose from sisal fiber, flax, rice husk, corn stover, cotton and commercialized microcrystalline cellulose are $85.9 \%, 84.9 \%, 76 \%, 80.6 \%, 94 \%$ and $81.7 \%$ respectively. Although, crystallinity values of $54 \%, 59 \%$ and $64 \%$ have been observed for nanofibers cellulose achieved from wood, flax and rutabaga. ${ }^{133}$ However, the crystallinity of nanofibrils from soy hull and wheat straw were demonstrated to be $70 \%$ and $78 \%$ respectively. ${ }^{210,211}$ Alternatively, very lower values (30-40\%) have been noted for beet pulp.

1.5.2. Effect of modification on the toxicity of nanocellulose. Based on the ecotoxicological evaluations with a variety of aquatic breeds, cellulose nanocrystals have lower toxin levels, as well as minimal environmental dangers (e.g., to daphnia, rainbow trout, as well as fathead minnow). In addition, cytotoxicity (the intracellular poisonous effect) and proinflammatory reactions are significantly lower than for multiwalled carbon nanotubes and crocidolite. ${ }^{212,213}$ As well as the genotoxicity in vitro, cellulose nanofibrils show virtually no side effects. In vitro toxin levels of bacterial cellulose nanofibers have been effectively investigated via the cell viability and even cytometric flow assays, together with in vivo analysis in mice. Bacterial cellulose often exhibits virtually no side effects in a culture of human umbilical vein endothelial cells, fibroblasts, as well as chondrocytes in humans. In addition, in vitro studies show that $95 \%$ of the mesenchymal stem cells accumulate in the cellulose membrane. ${ }^{214,215}$

1.5.3. Effect of modification on the biodegradability of nanocellulose. A significant advantage of biopolymer-dependent environment-friendly composites is their inherent biodegradability. Nevertheless, for biodegradation to occur rapidly, a large number of artificial biopolymers need energy-intensive composting temperatures $\left(60{ }^{\circ} \mathrm{C}\right)$. In comparison, both indigenous cellulose and regenerated cellulose can degrade quickly at ambient temperatures. ${ }^{216,217}$

1.5.4. Effect of modification on the specific surface area. Nanocellulose possesses an excellent specific surface area. Generally, cellulose nanoparticles have a specific surface area in the range of 50 to $200 \mathrm{~g} \mathrm{~m}^{-2}$. Alternatively, nanocellulose aerogels possess a specific surface area from 250 to $350 \mathrm{~m}^{2} \mathrm{~g}^{-1}$ as well as having an extremely low density $\left(0.02 \mathrm{~g} \mathrm{~cm}^{-3}\right)$ and a substantial porosity of $98 \%$. In the case of cellulose nanocrystals, particle aggregation takes place in the event of cellulose nanocrystals being completely dried or dried slightly beyond their critical concentration, resulting in a decrease in the features, as well as the functionality. Surfactants or surface modification may be used to prevent aggregation during drying in order to eliminate this issue. ${ }^{171}$

1.5.5. Effect of modification on the aspect ratio. The aspect ratio, which is known as the ratio of the length to width, is a significant parameter for cellulosic nanomaterials. The anisotropic phase formation and reinforcing properties are determined. The mechanical percolation method is also well-known to be very important for describing the mechanical behavior of the nanocomposites based on cellulose nanomaterials when prepared using casting/evaporation. In addition, tensile tests performed on films prepared using water evaporation of a series of CNC suspensions have shown that their tensile modulus increases as the aspect ratio of the nanoparticles increases, as shown in films, the tensile index and the triethylamine (TEA) index can also be analyzed by dewatering to assess the consistency of the MFCs or CFs. CNCs and CNFs, however, cannot be used. Difficulties associated with evaluating the length render it impossible for the CNFs to determine its worth. ${ }^{13,218}$ When increasing the oxidation strength of TEMPOpretreated fibers, ${ }^{218,219}$ they are considered to be very high, but strongly reduced. The aspect ratio is easier to determine for CNCs and it has been found to depend on both the cellulose source and the conditions of hydrolysis. The aspect ratio ranges from 10 to higher than 100 for cotton and soyhull respectively.

1.5.6. Effect of modification on the mechanical properties. In contrast to the $100 \%$ pure polymer content, improved rigidity, toughness, strength, barrier features, and even flame retardancy can be achieved by adding nanomaterials in the form of fillers in composite materials. ${ }^{212,220,221}$ As a consequence of the large surface area of the nanoparticles, the introduction of a small proportion of nanomaterials is necessary for these changes. In contrast to carbon nanotubes, the strength of wood cellulose nanofibers is only a quarter of that of the carbon nanotubes, but the price of cellulose nanofibers is lower than the price of carbon nanotubes, making the woodbased nanomaterial more desirable for unique applications. ${ }^{222}$ The strengthening ability of the cellulose whiskers stems from their excessive surface area. ${ }^{216,223,224}$

1.5.7. Effect of modification on the thermal properties. A film forms if cellulose nanomaterial suspensions are dried, which has a very poor thermal expansion coefficient (TEC), because of both the high crystallinity and strength of nanocellulosic network interactions. In order to reduce the TEC of the polymer nanocomposite sheets, the low TEC of the cellulose nanoparticles can be used if the strength of the network is sufficiently high enough to limit the thermal capacity. Although, the low thermal stability of cellulose nanomaterials can, at high temperatures, restrict the usage and manufacturing conditions of their nanocomposites. ${ }^{216,220}$ This problem is especially important for $\mathrm{H}_{2} \mathrm{SO}_{4}$ hydrolyzed $\mathrm{CNC}$, which, compared to the raw starting material or other types of nanocellulose, exhibits a dramatically reduced thermal stability. This is due to the classes of sulfate esters. ${ }^{225,226}$

1.5.8. Effect of modification on rheological properties. The suspension of cellulose nanofibers shows a propensity to shearthinning, as well as pseudoplasticity, which also depends on the $\mathrm{pH}$ of the environment. As a result of the electrostatic interactions, sulfate cellulose shows a $\mathrm{pH}$-dependent viscosity profile. In addition, the suspension of cellulose nanofibers demonstrates a reduction in viscosity and an improvement in 
the shear rate. Furthermore, owing to the entangled network configuration, CNF also offers an outstanding elastic module. ${ }^{227}$

1.5.9. Effect of modification on the irreversible agglomeration of nanocellulose. Nanoparticles have clustering problems, either from the tendency to aggregate (irreversible) or agglomerate (reversible). Specific nanocellulose drying causes irreversible agglomeration that disturbs their size and, consequently, their unique extraordinary properties. This irreversible agglomeration is known as hornification and is related to the existing hydrogen bonds. Agglomeration is avoided when freeze-drying, or even supercritical dying of $\mathrm{CO}_{2}$, is used. ${ }^{217}$

\subsection{Applications of biopolymer nanocellulose}

Cellulosic nanocomposites are the most preferred nanomaterial for large scale applications in various fields, as shown in Table 3, such as enzyme immobilization which helps in bio-conjugation, the non-covalent deposition and adsorption process, the isolation of antimicrobial and biomedical polymeric materials, biosensing, green catalysis ${ }^{151}$ and the production of drug carrier medicines ${ }^{228}$ in therapeutic and diagnostic applications, which offer superior advantages in drug delivery applications owing to their effective properties such as a smaller size, biocompatibility, stability and hydrophilicity and so on. ${ }^{16,30,31,229}$ In nanomaterials there is larger surface area and availability of the negative charge during hydrolysis, due to this a large amount of drugs can be bound to the surface of polymeric nanomaterials, which have an optimal control capacity for activity/dosing. Biopolymer cellulosic nanomaterials have also been used for paper and composite industrial applications, as shown in Table $5 .^{30,172-179}$ Nanocellulosic materials are considered to be one of the most promising and effective scaffolds for the refinement of various cells, osteoblasts and chondroblasts, and nanocellulosic materials are one of the most favorable potential candidates for use in bone tissue regeneration and refinement. A membrane generated from BC (bacterial cellulose) and hydroxyapatite (Hap) was reported as a biomaterial for bone healing and regeneration, it showed the growth and refinement of osteoblast cells, a higher level of ALP (alkaline phosphatase) activity and maximum bone nodule generation. $^{231,232}$ Oprea et al. demonstrated the wider biomedical applications of nanocellulose hybrids functionalized from metal oxide nanoparticles, showing sensing properties which are necessary in MRI (magnetic resonance imaging), tissue engineering, bio separation, and drug loading and delivery (Fig. 9). ${ }^{232}$ Gao et al. reported the development of transparent NCP (nanocellulose paper) by coating it with acrylic resins, and mixed organic and inorganic halides to fabricate biodegradable, favorable, flexible and effective perovskite solar cells (PSCs), which showed a good stability, retaining more than $80 \%$ stability after bending 50 times. $^{233}$

Table 5 Various reported studies on the applications and reinforcement properties of biopolymer nanomaterials

Type of

biopolymer

S. no. composites Preparation route

1. BNCs

2. CNFs

acrylic

resins

3. NCCs

4. NCCs

5. NCCs

6. $\quad$ CNCs

7. CNFs

8. Polyimide Prepared through the

composites solution casting method. or CNCs
Mixture incorporation of graphene oxide (GO) onto BNCs and in situ reduction of GO in BNCs by hydrazine.

Prepared through solvent casting method.

Prepared through coprecipitation of ferrous and ferric chlorides/in situ reduction by sodium borohydride.

Synthesized by coprecipitation of ferric nitrate $\left(\mathrm{Fe}_{3}\left(\mathrm{NO}_{3}\right)_{3}\right)$ and ferrous sulphate $\left(\mathrm{FeSO}_{4}\right)$ or via $\mathrm{FeCl}_{2}$ and $\mathrm{FeCl}_{3}$.

Synthesized by $\mathrm{Zn}(\mathrm{AcO})_{2}$, silver nitrate $\left(\mathrm{AgNO}_{3}\right) /$ in situ precipitation or via self-assembly. Synthesized via latex assembly approach.

Prepared by oxidizing dialdehyde CNFs.
Properties of composites with dimensions

Novel and emerging applications, 230

tensile strength, Young's modulus, favorable such as paper based electronics,

conductivity and the formation of variable sensors, antibacterial activities

$\mathrm{wt} \%$ reduced graphene oxide nanoparticles and so forth. (rGONPs) in the medium.

More transparency, reduction in value of abrasion loss, maximum improvement in Young's modulus, hardness and $0.08-0.48$ wt\% of initiator.

High stability and biocompatibility of $\mathrm{Fe}_{3} \mathrm{O}_{4}$ Enzyme immobilization and nanoparticles with 10-20 nm dimension/ gold nanoparticles with 3-7 nm dimensions.

High volume applications, for 237 example adsorption, separation of contaminants from waste water.

238 and 239 catalysis applications.

High stability, surface area of $\mathrm{Fe}_{3} \mathrm{O}_{4}$ nano- Various applications in drug particles with dimensions less than $100 \mathrm{~nm}$. removal and magnetic nanohybrids.

Larger surface area and biocompatibility of Various applications in the $\mathrm{ZnO}-\mathrm{Ag}$ nanoparticles with 9-35 $\mathrm{nm}$ and for generation of antibacterial $\mathrm{ZnO}$ nanoparticles dimension is between materials. 10-30 $\mathrm{nm}$.

Lower electrical conductivity, greater stability, resistivity and reversible resistance properties with a smaller size.

Higher surface area and smaller size of oxidized dialdehyde CNFs as compared to untreated ones.

Greater thermal stability, porosity, reduced density and shrinkage during aging.
Applications in bio-sensing.

In tissue engineering and wound 30 and 245 dressing.

Application in formation of in sensors, catalysts, adsorbents, and so forth. aerogel materials which are used 


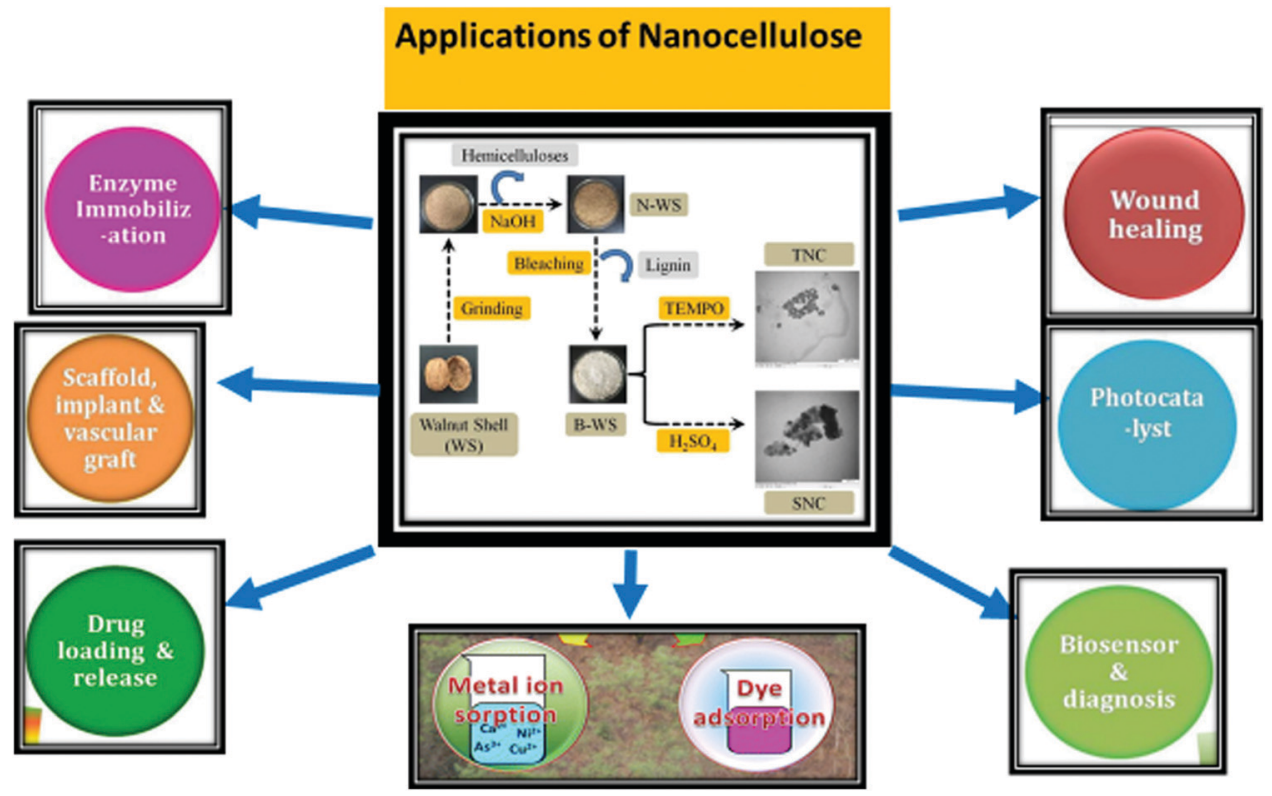

Fig. 9 Various applications of biopolymer nanocellulose.

Hoeng et al. demonstrated the applications of nanocellulosic materials in printed electronics, by fabricating self-standing and thermally stable films, the fabrication involved wide ranging processing approaches, applications of ink, and resulted in the generation of flexible and cost effective storage devices. ${ }^{234}$ Nanocellulosic biomaterials are also used as electrodes, electrolytes, converting devices, separators and binders in lithium ion batteries. ${ }^{235}$ Athukoralalage et al. reported the applications of 3D printed hydrogels in tissue engineering which involve a crosslinked network of hydrophilic biopolymer chains and have a larger water holding capacity. ${ }^{236}$

1.6.1. Nanocellulose in catalytic applications. In the area of catalysis, interest in green methods has developed gradually. Nanoparticles of metal and metal oxides have been used as catalysts for the purification of waste water, the esterification of long-chain fatty acids for the processing of biofuels, decontamination and chemical production. For catalytic applications, $\mathrm{Ag}, \mathrm{Au}, \mathrm{Pd}, \mathrm{Pt}, \mathrm{Cu}, \mathrm{Ru}, \mathrm{Cu}-\mathrm{Pd}$, and $\mathrm{CuO}$-nanocellulose hybrid composites have all been tested. Under a decreased atmosphere for catalytic hydrogenation and Heck coupling reactions, CNC was functionalized with Pd nanoparticles. CNC was compared to $\mathrm{Al}_{2} \mathrm{O}_{3}$ and $\mathrm{C}$ supports, showing that the $\mathrm{CNC}$ had an equal or higher activity than the other supports, but requires less Pd, resulting in a $90 \%$ conversion. It seems that the surface of the $\mathrm{CNC}$ is actively engaged in catalytic reactions. To assist the Pd nanoparticles, cellulose sponges prepared using double crosslinking cellulose with $\gamma-\mathrm{C}_{9} \mathrm{H}_{20} \mathrm{O}_{5} \mathrm{Si}$ (glycidoxypropyltrimethoxysilane) and PDA (polydopamine) have been used. The heterogeneous Suzuki and Heck cross-coupling reactions were successfully applied to this recyclable catalyst. Palladium leaching was negligible, and the catalyst could be removed and reused easily from the reaction mixture. Compared to traditional polymer-supported metallic NPs, these novel materials display an excellent turnover frequency, and the strategy allows
I noble metals to be used more effectively by using abundant natural bioresources as a support. ${ }^{51,52,54}$ The higher performance stems from the increased dispersity of the size of the nanoparticle and its improved coverage of the support surface. During ketone hydrogenation reactions, which are thought to occur through multiple hydrogen bonds between the CNC surface and the substrate, TEMPO-oxidized CNF has been shown to induce enantioselectivity (with an enantiomeric excess of up to $65 \%$ ), allowing the copper ions to prepare the catalytic material through the Huisgen click reaction. ${ }^{122,250,251}$ Likewise, in order to create composite structures with an excellent catalytic activity, $\mathrm{Ag}$, magnetite $\left(\mathrm{Fe}_{2} \mathrm{O}_{3}\right)$, and $\mathrm{Au}$ nanoparticles have been integrated into nanocellulose supports. ${ }^{20}$

1.6.2. Nanocellulose in engineering and electronic applications. Lightweight, versatile supercapacitors are the most critical potential opto-electronic applications of nanocellulosic materials. In order to provide a high volumetric capacitance, nanocellulose provides the required mechanical support for freestanding and flexible materials and is combined with a conductive material, usually a polymer. Polypyrrole (PPy), poly-ethylenedioxythiphene (PEDOT) and polyaniline (PANI) are the most common conductive polymers used. Nyström et al. synthesized the CNF-derived electroactive composites through the coating of cellulose fibrils with PPy. In addition, this composite was conductive and could also store energy. ${ }^{13,23,217}$ A material with an almost ideal pseudocapacitive response was developed by optimization of the PPy nanocellulose method. CNF has recently been used as a precursor to carbon nanofibers, creating a sodium ion battery anode. In organic light-emitting diodes, CNF has also been used to coat cellulose with an indium tin oxide film. As they are lightweight and have a good thermal and chemical stability, conductive nanocellulosic papers are promising materials for the production of flexible electronics. For example, CNC and silver have been 3D printed into conductive tracks with a high resolution, reducing the 
amount of silver required. Metal oxide nanocellulosic materials have also been studied as electrical materials that are thermally insulating. In contrast to the $\mathrm{ZnO}$ film alone, the development of a ZnO TEMPO-oxidized nanocellulose film showed a reduction of an order of magnitude in the thermal conductivity. ${ }^{52,221}$

1.6.3. Nanocellulose in medical applications. Nanocellulose holds promise for use in biomedical applications owing to its mechanical features, its nano fibrous chain and its ecofriendly nature, which is a perquisite for consumers in terms of health materials. Researchers have been searching for a material with osteoinductive and osteoconductive features and a surface composition similar to the ecofriendly extracellular matrix to enhance material interactions, within the comprehensive research field of biomaterial isolation for applications in bone engineering. BNCs have been developed as efficient biopolymers and, because of their high mechanical properties, biocompatibility, and minimum cytotoxicity, they have been widely used as a matrix for the isolation of biomaterials for applications in regenerative medicine and tissue engineering. Saska and coworkers have recently demonstrated that a nanocellulosiccollagen-apatite nanocomposite interlinked with an osteogenic growth peptide can be efficiently used for bone regeneration. It has been noted that nanocellulose is non-cytotoxic and therefore it has been suggested to promote cell augmentation as a tissue culture phase. ${ }^{10,23}$ Recently, Petreus and his coworkers demonstrated the cytotoxicity for tissue scaffold substance for water soluble $\mathrm{H}_{3} \mathrm{PO}_{3}$ (phosphorus acid) modified nanocellulose. Nanocellulose derivatized by $\mathrm{H}_{3} \mathrm{PO}_{3}$ was synthesized by reacting it with a molten mixture of $\mathrm{H}_{3} \mathrm{PO}_{3}$ and $\mathrm{CH}_{4} \mathrm{~N}_{2} \mathrm{O}$ (urea) microcrystalline cellulose. Owing to their non-toxic nature, the obtained water-soluble films were subjected to cell compatibility studies and found to exhibit a strong cytocompatibility. ${ }^{16,17,52}$ Functionalized nanocellulosic biomaterials are especially applicable to tissue and bone engineering owing to their mechanical properties and biocompatibility with other biological materials, for example, apatite and collagen. As a biocompatible material, phosphorylated nanocellulose has been examined as a scaffold for bone regeneration. ${ }^{38,43,198,252}$ Once implanted, phosphorylated cellulose promotes the precipitation of calcium phosphate, and the material closely resembles bone. Nanocellulose-based poly-vinyl alcohol $\left(\mathrm{C}_{2} \mathrm{H}_{4} \mathrm{O}\right)_{x}$ based hydrogels have been proposed for ophthalmic advances, as these composite materials are soft and flexible. They can also be translucent and can have a water content of almost $90 \%$. If $\left(\mathrm{C}_{2} \mathrm{H}_{4} \mathrm{O}\right)_{x}$ cellulose nanocomposite films are exposed to pressure, they undertake a nanocellulose alignment reconfiguration, visualized using measurements of the double refraction. Significant characteristics, such as targeting, enhanced solubility, maintained drug release, reduced clearance, a therapeutic effect and drug stability are exhibited by these efficient drug delivery systems. Owing to their colloidal stability, high surface-to-volume ratio and negative charge surface, which permitted the loading of neutral or charged drugs, the dominance of the deliverance of active substances and the transport of genes to the target cells, and the low drug-loading behavior of CNCs, significant efforts have been devoted to the use of CNCs in the pristine form as an appropriate and efficient pharmaceutical carrier and binder. Therefore, to enhance the binding of hydrophobic drugs, and owing to the presence of the reactive functional groups on the CNC backbone, a broad variety of surface modifications of CNCs have been carried out based on the chemical incorporation of chemical groups. ${ }^{140,142}$ However, after the modification processes, controlling the composition of CNCs requires further alterations to improve the effectiveness of the CNC-derived drug delivery systems. The researchers suggested that epirubicin could be released from $\mathrm{pH}$-responsive carriers based on CNCs and that the drug-containing complexes acquired could preserve their anticancer capability. Tang et al. recently reported a novel colon-targeted drug release mechanism developed by conjugating maleic anhydride CNCs (MCNCs) with the model drug (tosufloxacintosilate). ${ }^{217,224}$ They revealed that MCNC can effectively trap the model drug, and thus an excellent behavior was observed for colon targeted release. Ntoutoume et al. created complexes containing $\mathrm{CNC} /$ curcumin/cyclodextrin to target colon and prostate cancer cells in another study (Ntoutoume et al., 2016). They showed that, compared to curcumin alone, such complexes exhibit an important antiproliferative effect on cancer cells. CNC-based hydrogels, on the other hand, offer interesting bioavailability and, owing to their high surface area and open pore structure, can provide a superior drug delivery capacity. As shown by the latest published articles, intensive research work has recently been carried out. More recently, using CNCs and chitosan, Xu et al. produced a novel nanocomposite hydrogel and used it as a carrier for the controlled delivery of theophylline. They reported that such biocomposites exhibit excellent drug-controlled release behavior and can be used as a major carrier for the delivery of gastric-specific drugs. Jeddi et al. prepared carboxymethyl CNC in another research study, which was used in the formulation of bilayer alginate-chitosan hydrogel beads to produce smart, friendly, and magnetically sensitive hydrogel beads that were successfully applied as a dexamethanose delivery carrier. They demonstrated that the simple green production method developed using costeffective feedstocks provided a highly efficient drug delivery carrier. $^{17,55,251-253}$

1.6.4. Nanocellulose as a fire retardant. A rare combination of a good thermal stability and low flammability is provided by using phosphorylated cellulose. Low thermal stability and high flammability, burning without charring, can characterize native cellulose and most of its derivatives. Halogen, phosphorus, nitrogen, metal ions, and nanofiller-based flame retardants have been used, with the most effective being halogen-based. The applications of halogen-based flame retardants, however, has both ecological and health consequences, because halogens are toxic compounds that leach into the environment from the polymer matrix, accumulating in living beings. Moreover, upon combustion, they may release toxic gases. Compounds based on phosphorus promote char formation instead of combustible volatile species. Owing to the reaction between the flame retardant (e.g., phosphorus acids and their salts) and the carbon source, a char layer is formed in intumescent flame retardants. ${ }^{23,143,190,210}$ The material is insulated by this layer of char, retarding the spread of fire. Cellulose, with its high carbon composition, can be used in intumescent flame retardants to act 
as a carbon source. External flame retardants are used in many ways, such as diammonium hydrogen phosphate (DAP or $\left.\left(\mathrm{NH}_{4}\right)_{2} \mathrm{HPO}_{4}\right)$ and ammonium sulfate $\left(\left(\mathrm{NH}_{4}\right)_{2} \mathrm{SO}_{4}\right)$. There are certain advantages to attaching a flame retardant, such as phosphate groups, to cellulose via covalent bonding over external flame retardants. ${ }^{52,251}$

1.6.5. Nanocellulose in sensing. The identification of various molecules in the environment, including small molecules, macromolecules, and biomolecules, is necessary to protect human health and ensure well-being. The global sensor market is expected to rise at an annual pace of more than $10 \%$, reaching $\$ 20$ billion by 2020 , driven by increased global competition in manufacturing and further developments in pollution control, biomedical applications and health care. Health care sensors and biomedical applications are of rising significance. Chemical sensors for customer health monitoring (e.g., for glucose and cholesterol), for home use and biocompatible materials for use in implants and prostheses, are key areas in the biomedical sector. Sensors also play a role in the prevention of accidental fires, environmental atmospheric monitoring and industrial processing of toxic and dangerous gases. The photonic, colloidal, and surface properties of nanocellulose-based materials make them very attractive sensors, as discussed in a recent study. It has been shown that pure bacterial cellulose films produced using, for example, wild type and recombinant Komagataeibacter xylinus (K. xylinus) have a significant intrinsic piezoelectricity; this type of nanocellulose could therefore be incorporated into piezoelectronic biosensors. ${ }^{17,217,252,254,255}$ To assist fluorescent carbon quantum dots, TEMPO-oxidized nanocellulose has been used to form a hydrogel. Upon identification of laccase enzymes, this hybrid material was used to track fluorescent quenching. The nanocellulose hydrogel matrix increased the fluorescent signal strength without changing the wavelengths of excitation or the emission. Owing to a beneficial interaction between the hydrogel and fluorophore surfaces, this was a result of the greater dispersion of the carbon quantum dots in the hydrogel compared to that observed in the absence of nanocellulose. TEMPO radical oxidized NFCs have also been used as a medium for the immobilization of C-phycocyanin, a sensing biomolecule that can act as an efficient copper ion detection biosensor. ${ }^{31}$

1.6.6. Nanocellulose in adsorption, separation, decontamination, and filtration. Applications in water and air purification, catalytic degradation of toxic organic compounds, oil contamination adsorbents, repellents, sensors for waterborne pathogens and high-performance energy conversion devices can be fabricated using nanocellulose composites. A recent review reported the use of nanocellulose as an adsorbent for environmental remediation. In adsorption and separation, nanocellulose is typically valued owing to its high hydrophilicity, as well as its morphology and mechanical properties to form supports and membranes. In chromatographic columns, nanocellulose-based systems have been used to separate the chiral enantiomers necessary for pharmaceutical, clinical, food and environmental sciences. ${ }^{144,179,256}$ Traditionally, various chromatographic techniques, such as high-pressure liquid chromatography (HPLC), gas chromatography (GC), supercritical fluid chromatography (SCFC), and capillary liquids have been used.
As a result, capillary electro-chromatography, especially open tubular capillary electrochromatography, has evolved as an alternative efficient chiral stationary phase suitable for single-pair separation of enantiomers and capillary liquid chromatography (CLC), has been used to separate chiral enantiomers. However, owing to the long analysis times and the use of very costly chiral stationary phases, these methods are not ideal. Nanocellulose is capable of converting a chiral liquid into the crystalline phase at a critical concentration and can be used as a valuable chiral stable phase with a uniform hydrophobicity and hydrophilicity. For enantio separation, nanocellulose crystals altered using 3,5dimethylphenyl isocyanate were used as a tubular column capillary. These reveal the good lifetime of the column, as well as the stability and repeatability over many cycles and the applicability for many pairs of enantiomers. In water purification technologies, nanocellulose materials are used owing to their high water permeability, elevated surface area, excellent mechanical features and efficient surface composition. The efficiency of nanocellulose metallized with Ag and Pt nanocomposites, in the form of thin film composites under forward osmosis water treatment, was demonstrated in a recent study by Tato and co-workers. Higher water fluxes and solution rejections for wastewater samples were seen using this composite. For $\mathrm{Ag}^{+}, \mathrm{Cu}^{2+}$, and $\mathrm{Fe}^{3+}$ metal ions, nanocellulose membranes have been prepared as adsorbents. The native nanocellulose had pores that were too small and fibers that were too thick to allow the membrane to penetrate water rapidly. The surface roughness and filtration time were improved by functionalizing the membrane with TEMPO. ${ }^{17,82,139,209,257}$ It appears that the metal ions are first coordinated by the carboxylate groups $(-\mathrm{COOH})$ in the TEMPO-functionalized nanocellulose system. Enzymatically phosphorylated nanocellulose adsorbents were used to separate metal ions $\left(\mathrm{Ag}^{+}, \mathrm{Cu}^{2+}\right.$, and $\left.\mathrm{Fe}^{3+}\right)$ from an aqueous industrial effluent model in a study published by Liu et al. The functionality and sorption behavior of nanocellulose has been significantly improved by phosphorylation. About $99 \%$ of the $\mathrm{Cu}^{2+}$ and $\mathrm{Fe}^{3+}$ specificity for a specific analyte can be extracted using phosphorylated nanocellulose with appropriate consideration of the surface chemistry. A strong affinity for $\mathrm{Cr}(\mathrm{vI})$ was provided using CNF surface modification with dopamine, in which Fe(III) cross-linked CNFs adsorbed As(v) better than the other surface functions. To eliminate copper from the aqueous mixture, Mautner et al. used phosphorylated nanocellulose paper. The phosphorylating agent used was $\mathrm{H}_{3} \mathrm{PO}_{4}$. Larger concentrations of $\mathrm{Cu}^{2+}$ were readily adsorbed by the functional groups on the nanopaper surface compared with the $\mathrm{PO}_{4}{ }^{3-}$ (phosphate groups) between the interior of the nanopaper. ${ }^{52,140}$

\section{Conclusion}

Nanocellulose synthesized from cellulosic waste materials has effective, promising and environmentally friendly properties, such as a larger crystallinity, Young's modulus, aspect ratio and tensile strength, non-toxicity and biodegradable nature, and can be obtained from the natural MFCs (micro-fibrillated 
cellulose) which upgrades the technology for use in waste management and waste utilization. Unmodified nanocellulose has applications in various fields, but the functionalization of nanocellulosic materials provides greater enhancements in terms of their properties, for example, the maximum active binding sites, ion exchange properties and availability of active functional groups which broaden the area of research in many fields such as adsorption, separation, bio-catalysis, antimicrobial activities, waste water treatment, other large scale industrial applications and so on. Pretreatment methods are necessary for the economically effective origination of CNFs, as they can effectively reduce the energy consumption needed throughout the mechanical degradation treatment. Thus, research into novel, superior, effective, environmentally friendly and favorable pre-treatment methods remains a mandatory objective. This review explains the various routes available for the functionalization of cellulose and concludes that some routes possess many critical issues, such as the generation of a large amount of acid containing water during the process of acid hydrolysis, greater energy requirements in the case of mechanical pre-treatment and the longer reaction times that are necessary for enzymatic hydrolysis treatment. In addition to the conventional mechanical and chemical treatment processes traditionally used to isolate CNFs and CNCs, other promising production techniques and pretreatment processes have been proposed to develop an economically efficient and environmentally friendly production route for nanocellulose. Undoubtedly, biopolymer nanocellulose has extraordinary potential for the development of a novel and effective biomedical material. Functionalized nanocellulosic biomaterials are especially applicable to tissue and bone engineering owing to their mechanical properties and biocompatibility with other biological materials, such as apatite and collagen. As a biocompatible material, phosphorylated nanocellulose has been examined as a scaffold for bone regeneration. The present review shows that nanocellulose demonstrates the potential to be a truly green nanomaterial, with several outstanding useful features such as a large surface area, adaptable surface chemistry, better mechanical properties and anisotropic shape; these features, among others, makes it an excellent material for a wide range of applications in the field of biomedical engineering and materials science, and it has a high potential for development for use in industry.

\section{Future scope}

1. By generating effective, more favorable properties with cost effective modifications and isolation techniques for biopolymer nanocellulose, it promotes the research towards more acceptance chances as a commercially available biomaterial in various largescale applications. Therefore, future advances emphasizing the cost effective and eco-friendly routes of nanocellulose extraction and modification will promote the expeditious and favorable growth of this "wonder" biomaterial for industrial applications.

2. The phosphorylation route for the functionalization of nanocellulose is the most effective route owing to its inexpensive and eco-friendly nature and thus, it will be used to explore the future advances in the field of homogeneous catalysis by creating sustainable and recyclable biocatalysts with a greater selectivity and activity.

3. Functionalization through grafting is also considered to be a superior route because it enhances the properties of biopolymer cellulose, providing significant advances. Thus, future research will focus on the advances and applications of new monomers using different optimized grafting conditions.

\section{Conflicts of interest}

There are no conflicts to declare.

\section{References}

1 M. Asim, K. Abdan, M. Jawaid, M. Nasir, Z. Dashtizadeh, M. R. Ishak, M. E. Hoque and Y. Deng, Int. J. Polym. Sci., 2015, 2015.

2 D. S. Malik, C. K. Jain and A. K. Yadav, Appl. Water Sci., 2017, 7, 2113-2136.

3 D. Sud, G. Mahajan and M. P. Kaur, Bioresour. Technol., 2008, 99, 6017-6027.

4 A. Alemdar and M. Sain, Bioresour. Technol., 2008, 99, 1664-1671.

5 R. Kumar, R. K. Sharma and A. P. Singh, J. Mol. Liq., 2017, 232, 62-93.

6 J. Lamaming, R. Hashim, C. P. Leh, O. Sulaiman, T. Sugimoto and M. Nasir, Carbohydr. Polym., 2015, 134, 534-540.

7 H. P. S. Abdul Khalil, A. F. I. Yusra, A. H. Bhat and M. Jawaid, Ind. Crops Prod., 2010, 31, 113-121.

8 V. Thakur, E. Sharma, A. Guleria, S. Sangar and K. Singh, Mater. Today: Proc., 2020, 32, 608-619, DOI: 10.1016/ J.MATPR.2020.02.756.

9 Y. Habibi, L. A. Lucia and O. J. Rojas, Chem. Rev., 2010, 110, 3479-3500.

10 Y. Habibi, Chem. Soc. Rev., 2014, 43, 1519-1542.

11 P. Phanthong, P. Reubroycharoen, X. Hao, G. Xu, A. Abudula and G. Guan, Carbon Resour. Convers., 2018, 1, 32-43.

12 T. Abitbol, A. Rivkin, Y. Cao, Y. Nevo, E. Abraham, T. BenShalom, S. Lapidot and O. Shoseyov, Curr. Opin. Biotechnol., 2016, 39, 76-88.

13 A. Dufresne, Mater. Today, 2013, 16, 220-227.

14 A. Dufresne, Nanocellulose, De Gruyter, 2012.

15 D. Klemm, F. Kramer, S. Moritz, T. Lindström, M. Ankerfors, D. Gray and A. Dorris, Angew. Chem., Int. Ed., 2011, 50, 5438-5466.

16 N. Lin and A. Dufresne, Eur. Polym. J., 2014, 59, 302-325.

17 M. Nasir, R. Hashim, O. Sulaiman and M. Asim, CelluloseReinforced Nanofibre Composites: Production, Properties and Applications, Elsevier Inc., 2017, pp. 261-276.

18 A. Isogai, J. Wood Sci., 2013, 59, 449-459.

19 F. Jiang and Y. Lo Hsieh, Carbohydr. Polym., 2013, 95, 32-40.

20 A. A. Oun and J. W. Rhim, Mater. Lett., 2016, 168, 146-150. 
21 S. H. Osong, S. Norgren and P. Engstrand, Cellulose, 2016, 23, 93-123.

22 Laccase aided modification of nanofibrillated cellulose with dodecyl gallate:: BioResources, https://bioresources. cnr.ncsu.edu/resources/laccase-aided-modification-of-nanofibrillated-cellulose-with-dodecyl-gallate/, (accessed 4 September 2020).

23 G. Siqueira, J. Bras and A. Dufresne, Polymers, 2010, 2, 728-765.

24 B. Kluczek-Turpeinen, M. Tuomela, A. Hatakka and M. Hofrichter, Appl. Microbiol. Biotechnol., 2003, 61, 374-379.

25 A. K. Chandel, B. C. M. Gonçalves, J. L. Strap and S. S. Da Silva, Crit. Rev. Biotechnol., 2015, 35, 281-293.

26 R. J. Moon, A. Martini, J. Nairn, J. Simonsen and J. Youngblood, Chem. Soc. Rev., 2011, 40, 3941-3994.

27 N. Lavoine, I. Desloges, A. Dufresne and J. Bras, Carbohydr. Polym., 2012, 90, 735-764.

28 H. P. S. Abdul Khalil, Y. Davoudpour, M. N. Islam, A. Mustapha, K. Sudesh, R. Dungani and M. Jawaid, Carbohydr. Polym., 2014, 99, 649-665.

29 R. Singla, A. Guliani, A. Kumari and S. K. Yadav, Nanoscale Materials in Targeted Drug Delivery, Theragnosis and Tissue Regeneration, Springer Singapore, 2016, pp. 103-125.

30 B. Thomas, M. C. Raj, B. K. Athira, H. M. Rubiyah, J. Joy, A. Moores, G. L. Drisko and C. Sanchez, Chem. Rev., 2018, 118, 11575-11625.

31 K.-M. Chin, S. Sung Ting, H. L. Ong and M. Omar, J. Appl. Polym. Sci., 2018, 135, 46065.

32 S. Bagheri and N. M. Julkapli, Biopolymer Grafting: Synthesis and Properties, Elsevier Inc., 2018, pp. 521-549.

33 S. Hansson, V. Trouillet, T. Tischer, A. S. Goldmann, A. Carlmark, C. Barner-Kowollik and E. Malmström, Biomacromolecules, 2013, 14, 64-74.

34 J. George and S. N. Sabapathi, Nanotechnol., Sci. Appl., 2015, 8, 45-54.

35 A. Vashist and A. K. K. Kaushik, Nanogels for Biomedical Applications Smart Materials Series Editors: Titles in this Series, 2017.

36 K. Raemdonck, J. Demeester and S. De Smedt, Soft Matter, 2009, 5, 707-715.

37 J. K. Oh, R. Drumright, D. J. Siegwart and K. Matyjaszewski, Prog. Polym. Sci., 2008, 33, 448-477.

38 Y. Ye, J. Yu and Z. Gu, Macromol. Chem. Phys., 2016, 217, 333-343.

39 C. Ganta, A. Shi, S. K. Battina, M. Pyle, S. Rana, D. H. Hua, M. Tamura and D. Troyer, J. Nanosci. Nanotechnol., 2008, 8, 2334-2340.

40 S. V. Vinogradov, A. D. Zeman, E. V. Batrakova and A. V. Kabanov, J. Controlled Release, 2005, 107, 143-157.

41 A. Umar, K. Singh, S. K. Mehta, H. Fouad and O. Y. Alothman, Nanosci. Nanotechnol. Lett., 2018, 10, 429-434.

42 K. Singh and S. K. Mehta, Sens. Lett., 2015, 13, 1002-1006.

43 A. V. Kabanov and S. V. Vinogradov, Angew. Chem., Int. Ed., 2009, 48, 5418-5429.

44 Y. Amamoto, H. Otsuka and A. Takahara, Nanotechnologies for the Life Sciences, Wiley-VCH Verlag GmbH \& Co. KGaA, Weinheim, Germany, 2012.
45 S. V. Vinogradov, Nanomedicine, 2010, 5, 165-168.

46 D. Klemm, B. Heublein, H. P. Fink and A. Bohn, Angew. Chem., Int. Ed., 2005, 44, 3358-3393.

47 M. Börjesson and G. Westman, Cellulose - Fundamental Aspects and Current Trends, InTech, 2015.

48 C. Somerville, Annu. Rev. Cell Dev. Biol., 2006, 22, 53-78.

49 R. E. Williamson, J. E. Burn and C. H. Hocart, Trends Plant Sci., 2002, 7, 461-467.

50 H. Wei, K. Rodriguez, S. Renneckar and P. J. Vikesland, Environ. Sci.: Nano, 2014, 1, 302-316.

51 D. Trache, M. H. Hussin, M. K. M. Haafiz and V. K. Thakur, Nanoscale, 2017, 9, 1763-1786.

52 D. Trache, A. F. Tarchoun, M. Derradji, T. S. Hamidon, N. Masruchin, N. Brosse and M. H. Hussin, Front. Chem., 2020, 8, 392.

53 V. Kumar, P. Guleria, N. Dasgupta, S. Ranjan, D. Trache, A. F. Tarchoun, M. Derradji, O. Mehelli, M. H. Hussin and W. Bessa, Functionalized Nanomaterials I, CRC Press, 2020, pp. 171-190.

54 D. Trache, V. K. Thakur and R. Boukherroub, Nanomaterials, 2020, 10, 1523.

55 H. Kargarzadeh, I. Ahmad, I. Abdullah, A. Dufresne, S. Y. Zainudin and R. M. Sheltami, Cellulose, 2012, 19, 855-866.

56 D. Trache, AIMS Mater. Sci., 2018, 5, 201-205.

57 A. Karimian, H. Parsian, M. Majidinia, M. Rahimi, S. M. Mir, H. Samadi Kafil, V. Shafiei-Irannejad, M. Kheyrollah, H. Ostadi and B. Yousefi, Int. J. Biol. Macromol., 2019, 133, 850-859.

58 I. Siró and D. Plackett, Cellulose, 2010, 17, 459-494.

59 S. Ahola, M. Österberg and J. Laine, Cellulose, 2008, 15, 303-314.

60 P. Li, J. A. Sirviö, A. Haapala and H. Liimatainen, ACS Appl. Mater. Interfaces, 2017, 9, 2846-2855.

61 J. Lu, P. Askeland and L. T. Drzal, Polymer, 2008, 49, 1285-1296.

62 H. Bäckdahl, B. Risberg and P. Gatenholm, Mater. Sci. Eng., $C, 2011,31,14-21$.

63 R. D. Gilbert and J. F. Kadla, Biopolymers from Renewable Resources, Springer Berlin Heidelberg, 1998, pp. 47-95.

64 M. Henriksson, L. A. Berglund, P. Isaksson, T. Lindström and T. Nishino, Biomacromolecules, 2008, 9, 1579-1585.

65 H. A. Silvério, W. P. Flauzino Neto, N. O. Dantas and D. Pasquini, Ind. Crops Prod., 2013, 44, 427-436.

66 M. J. John and S. Thomas, Carbohydr. Polym., 2008, 71, 343-364.

67 D. K. Patel, S. D. Dutta and K. T. Lim, RSC Adv., 2019, 9, 19143-19162.

68 E. E. Ureña-Benavides, G. Ao, V. A. Davis and C. L. Kitchens, Macromolecules, 2011, 44, 8990-8998.

69 H. El-Saied, A. H. Basta and R. H. Gobran, Polym.-Plast. Technol. Eng., 2004, 43, 797-820.

70 A. Bodin, H. Bäckdahl, H. Fink, L. Gustafsson, B. Risberg and P. Gatenholm, Biotechnol. Bioeng., 2007, 97, 425-434.

71 X. Zou, G. Wu, S. Stagge, L. Chen, L. J. Jönsson and F. F. Hong, Microb. Cell Fact., 2017, 16, 229. 
72 S. Zhang, F. Zhang, L. Jin, B. Liu, Y. Mao, Y. Liu and J. Huang, Cellulose, 2019, 26, 5177-5185.

73 B. Ram and G. S. Chauhan, Chem. Eng. J., 2018, 331, 587-596.

74 P. Satyamurthy and N. Vigneshwaran, Enzyme Microb. Technol., 2013, 52, 20-25.

75 Preparation of Spherical Nanocellulose by Anaerobic Microbial Consortium, https:/www.researchgate.net/publi cation/267244995_Preparation_of_Spherical_Nanocellulose_ by_Anaerobic_Microbial_Consortium, (accessed 19 September 2020).

76 N. Wang, E. Ding and R. Cheng, Langmuir, 2008, 24, 5-8.

77 Utilization of agro-residues (rice husk) in small waste water treatment plans.

78 A. S. Singha and A. Guleria, Eng. Agric., Environ. Food, 2015, 8, 52-60.

79 A. Mehta, K. K. Bhardwaj and R. Gupta, Green Polymeric Materials: Advances and Sustainable Development, Nova Science Publishers, Inc., 2017, pp. 123-146.

80 H. D. Nguyen, T. T. Thuy Mai, N. B. Nguyen, T. D. Dang, M. L. Phung Le and T. T. Dang, Adv. Nat. Sci.: Nanosci. Nanotechnol., 2013, 4, 015016.

81 R. Zuluaga, J. L. Putaux, A. Restrepo, I. Mondragon and P. Gañán, Cellulose, 2007, 14, 585-592.

82 E. Fortunati, F. Luzi, A. Jiménez, D. A. Gopakumar, D. Puglia, S. Thomas, J. M. Kenny, A. Chiralt and L. Torre, Carbohydr. Polym., 2016, 149, 357-368.

83 E. Abraham, B. Deepa, L. A. Pothen, J. Cintil, S. Thomas, M. J. John, R. Anandjiwala and S. S. Narine, Carbohydr. Polym., 2013, 92, 1477-1483.

84 M. G. Thomas, E. Abraham, P. Jyotishkumar, H. J. Maria, L. A. Pothen and S. Thomas, Int. J. Biol. Macromol., 2015, 81, 768-777.

85 C. Liu, B. Li, H. Du, D. Lv, Y. Zhang, G. Yu, X. Mu and H. Peng, Carbohydr. Polym., 2016, 151, 716-724.

86 B. Deepa, E. Abraham, B. M. Cherian, A. Bismarck, J. J. Blaker, L. A. Pothan, A. L. Leao, S. F. de Souza and M. Kottaisamy, Bioresour. Technol., 2011, 102, 1988-1997.

87 B. M. Cherian, L. A. Pothan, T. Nguyen-Chung, G. Mennig, M. Kottaisamy and S. Thomas, J. Agric. Food Chem., 2008, 56, 5617-5627.

88 N. Rambabu, S. Panthapulakkal, M. Sain and A. K. Dalai, Ind. Crops Prod., 2016, 83, 746-754.

89 J. Trifol, C. Sillard, D. Plackett, P. Szabo, J. Bras and A. E. Daugaard, Cellulose, 2017, 24, 107-118.

90 J. Li, X. Wei, Q. Wang, J. Chen, G. Chang, L. Kong, J. Su and Y. Liu, Carbohydr. Polym., 2012, 90, 1609-1613.

91 F. Jiang and Y. Lo Hsieh, Carbohydr. Polym., 2015, 122, 60-68.

92 E. Kalita, B. K. Nath, F. Agan, V. More and P. Deb, Ind. Crops Prod., 2015, 65, 550-555.

93 E. Espino, M. Cakir, S. Domenek, A. D. Román-Gutiérrez, N. Belgacem and J. Bras, Ind. Crops Prod., 2014, 62, 552-559.

94 E. Fortunati, D. Puglia, M. Monti, C. Santulli, M. Maniruzzaman and J. M. Kenny, J. Appl. Polym. Sci., 2013, 128, 3220-3230.
95 A. A. Oun and J. W. Rhim, Carbohydr. Polym., 2016, 150, 187-200.

96 T. H. Kim, R. Gupta and Y. Y. Lee, Methods Mol. Biol., 2009, 581, 79-91.

97 N. Sarkar, S. K. Ghosh, S. Bannerjee and K. Aikat, Renewable Energy, 2012, 37, 19-27.

98 Y. Park, Y. N. Hong, A. Weyers, Y. S. Kim and R. J. Linhardt, IET Nanobiotechnol., 2011, 5, 69.

99 H. Wang, J. Wang, Z. Fang, X. Wang and H. Bu, Int. J. Hydrogen Energy, 2010, 35, 8303-8309.

100 Y. H. P. Zhang, S. Y. Ding, J. R. Mielenz, J. B. Cui, R. T. Elander, M. Laser, M. E. Himmel, J. R. McMillan and L. R. Lynd, Biotechnol. Bioeng., 2007, 97, 214-223.

101 M. E. Himmel, W. S. Adney, J. O. Baker, R. Elander, J. D. McMillan, R. A. Nieves, J. J. Sheehan, S. R. Thomas, T. B. Vinzant and M. Zhang, Fuel \& Chemical from Biomass, 1997, 2-45.

102 J. W. Lee and T. W. Jeffries, Bioresour. Technol., 2011, 102, 5884-5890.

103 Y. Ogasawara, S. Itagaki, K. Yamaguchi and N. Mizuno, ChemSusChem, 2011, 4, 519-525.

104 M. Foston and A. J. Ragauskas, Biomass Bioenergy, 2010, 34, 1885-1895.

105 C. Li, B. Knierim, C. Manisseri, R. Arora, H. V. Scheller, M. Auer, K. P. Vogel, B. A. Simmons and S. Singh, Bioresour. Technol., 2010, 101, 4900-4906.

106 G. Panagiotou and L. Olsson, Biotechnol. Bioeng., 2007, 96, 250-258.

107 M. V. Bule, A. H. Gao, B. Hiscox and S. Chen, J. Agric. Food Chem., 2013, 61, 3916-3925.

108 M. T. García-Cubero, L. G. Palacín, G. González-Benito, S. Bolado, S. Lucas and M. Coca, Bioresour. Technol., 2012, 107, 229-234.

109 C. Li, L. Wang, Z. Chen, Y. Li, R. Wang, X. Luo, G. Cai, Y. Li, Q. Yu and J. Lu, Bioresour. Technol., 2015, 183, 240-247.

110 F. Talebnia, D. Karakashev and I. Angelidaki, Bioresour. Technol., 2010, 101, 4744-4753.

111 R. K. Sharma and R. Kumar, Int. J. Biol. Macromol., 2019, 134, 704-721.

112 F. Van Rantwijk, R. M. Lau and R. A. Sheldon, Trends Biotechnol., 2003, 21, 131-138.

113 G. Brodeur, E. Yau, K. Badal, J. Collier, K. B. Ramachandran and S. Ramakrishnan, Enzyme Res., 2011, 2011.

114 N. Sun, H. Rodríguez, M. Rahman and R. D. Rogers, Chem. Commun., 2011, 47, 1405-1421.

115 A. F. Metaxa, E. K. Efthimiadou, N. Boukos and G. Kordas, J. Colloid Interface Sci., 2012, 384, 198-206.

116 D. Appleby, C. L. Hussey, K. R. Seddon and J. E. Turp, Nature, 1986, 323, 614-616.

117 N. Akhtar, K. Gupta, D. Goyal and A. Goyal, Environ. Prog. Sustainable Energy, 2016, 35, 489-511.

118 X. Zhao, K. Cheng and D. Liu, Appl. Microbiol. Biotechnol., 2009, 82, 815-827.

119 E. C. Bensah and M. Mensah, Int. J. Chem. Eng., 2013, 719607. 
120 X. Wang, Y. Zhang, H. Jiang, Y. Song, Z. Zhou and H. Zhao, Mater. Lett., 2016, 183, 179-182.

121 M. Henriksson, G. Henriksson, L. A. Berglund and T. Lindström, Eur. Polym. J., 2007, 43, 3434-3441.

122 G. Siqueira, S. Tapin-Lingua, J. Bras, D. da Silva Perez and A. Dufresne, Cellulose, 2010, 17, 1147-1158.

123 A. de Campos, A. C. Correa, D. Cannella, E. de M. Teixeira, J. M. Marconcini, A. Dufresne, L. H. C. Mattoso, P. Cassland and A. R. Sanadi, Cellulose, 2013, 20, 1491-1500.

124 M. Pedersen and A. S. Meyer, New Biotechnol., 2010, 27, 739-750.

125 A. Karadag, B. Ozcelik and Q. Huang, J. Agric. Food Chem., 2014, 62, 1852-1859.

126 A. Kaushik and M. Singh, Carbohydr. Res., 2011, 346, 76-85.

127 Y. Wang, X. Wei, J. Li, F. Wang, Q. Wang, J. Chen and L. Kong, Fibers Polym., 2015, 16, 572-578.

128 A. N. Nakagaito and H. Yano, Appl. Phys. A: Mater. Sci. Process., 2004, 78, 547-552.

129 B. Wang and M. Sain, Polym. Int., 2007, 56, 538-546.

130 Q. Cheng, S. Wang and Q. Han, J. Appl. Polym. Sci., 2010, 115, 2756-2762.

131 S. Czernik, R. French, C. Feik and E. Chornet, Ind. Eng. Chem. Res., 2002, 41, 4209-4215.

132 A. Dufresne, D. Dupeyre and M. R. Vignon, J. Appl. Polym. Sci., 2000, 76, 2080-2092.

133 S. Eyley and W. Thielemans, Nanoscale, 2014, 6, 7764-7779.

134 T. Petreus, B. A. Stoica, O. Petreus, A. Goriuc, C. E. Cotrutz, I. V. Antoniac and L. Barbu-Tudoran, J. Mater. Sci.: Mater. Med., 2014, 25, 1115-1127.

135 T. Tzanov, M. Stamenova and A. Cavaco-Paulo, Macromol. Rapid Commun., 2002, 23, 962-964.

136 P. L. Granja, L. Pouységu, M. Pétraud, B. De Jéso, C. Baquey and M. A. Barbosa, J. Appl. Polym. Sci., 2001, 82, 3341-3353.

137 Y. Shi, D. Belosinschi, F. Brouillette, A. Belfkira and B. Chabot, Carbohydr. Polym., 2014, 106, 121-127.

138 J. Ma and Y. Sahai, Carbohydr. Polym., 2013, 92, 955-975.

139 P. Liu, P. F. Borrell, M. Božič, V. Kokol, K. Oksman and A. P. Mathew, J. Hazard. Mater., 2015, 294, 177-185.

140 T. Oshima, S. Taguchi, K. Ohe and Y. Baba, Carbohydr. Polym., 2011, 83, 953-958.

141 T. Tzanov, M. Stamenova and A. Cavaco-Paulo, Macromol. Rapid Commun., 2002, 23, 962-964.

142 G. Leone, P. Torricelli, R. Giardino and R. Barbucci, Polym. Adv. Technol., 2008, 19, 824-830.

143 C. Gérard, G. Fontaine and S. Bourbigot, Materials, 2010, 3, 4476-4499.

144 J. Lehtonen, J. Hassinen, A. A. Kumar, L. S. Johansson, R. Mäenpää, N. Pahimanolis, T. Pradeep, O. Ikkala and O. J. Rojas, Cellulose, 2020, 1-14.

145 A. C. Nuessle, F. M. Ford, W. P. Hall and A. L. Lippert, Text. Res. J., 1956, 26, 32-39.

146 J. C. Fricain, P. L. Granja, M. A. Barbosa, B. De Jéso, N. Barthe and C. Baquey, Biomaterials, 2002, 23, 971-980.

147 R. Arvidsson, D. Nguyen and M. Svanström, Environ. Sci. Technol., 2015, 49, 6881-6890.
148 L. Wågberg, G. Decher, M. Norgren, T. Lindström, M. Ankerfors and K. Axnäs, Langmuir, 2008, 24, 784-795.

149 I. Siró, D. Plackett, M. Hedenqvist, M. Ankerfors and T. Lindström, J. Appl. Polym. Sci., 2011, 119, 2652-2660.

150 O. Nechyporchuk, M. N. Belgacem and J. Bras, Ind. Crops Prod., 2016, 93, 2-25.

151 T. Saito, M. Hirota, N. Tamura, S. Kimura, H. Fukuzumi, L. Heux and A. Isogai, Biomacromolecules, 2009, 10, 1992-1996.

152 A. E. J. de Nooy, A. C. Besemer and H. van Bekkum, Recl. Trav. Chim. Pays-Bas, 1994, 113, 165-166.

153 S. Iwamoto, A. Isogai and T. Iwata, Biomacromolecules, 2011, 12, 831-836.

154 K. Xhanari, K. Syverud, G. Chinga-Carrasco, K. Paso and P. Stenius, Cellulose, 2011, 18, 257-270.

155 J. Araki, M. Wada and S. Kuga, Langmuir, 2001, 17, 21-27. 156 B. G. Rånby, Discuss. Faraday Soc., 1951, 11, 158-164.

157 J. F. Revol, H. Bradford, J. Giasson, R. H. Marchessault and D. G. Gray, Int. J. Biol. Macromol., 1992, 14, 170-172.

158 X. Mu and D. G. Gray, Langmuir, 2014, 30, 9256-9260.

159 H. Liimatainen, M. Visanko, J. A. Sirviö, O. E. O. Hormi and J. Niinimaki, Biomacromolecules, 2012, 13, 1592-1597.

160 A. Marmur, Soft Matter, 2012, 8, 6867-6870.

161 A. K. Bledzki, A. A. Mamun, M. Lucka-Gabor and V. S. Gutowski, eXPRESS Polym. Lett., 2008, 2, 413-422.

162 H. Yuan, Y. Nishiyama, M. Wada and S. Kuga, Biomacromolecules, 2006, 7, 696-700.

163 M. Bulota, K. Kreitsmann, M. Hughes and J. Paltakari, J. Appl. Polym. Sci., 2012, 126, E449-E458.

164 J. F. Sassi and H. Chanzy, Cellulose, 1995, 2, 111-127.

165 N. S. Çetin, P. Tingaut, N. Özmen, N. Henry, D. Harper, M. Dadmun and G. Sèbe, Macromol. Biosci., 2009, 9, 997-1003.

166 C. Eyholzer, P. Tingaut, T. Zimmermann and K. Oksman, J. Polym. Environ., 2012, 20, 1052-1062.

167 M. Hasani, E. D. Cranston, G. Westman and D. G. Gray, Soft Matter, 2008, 4, 2238-2244.

168 C. Goussé, H. Chanzy, M. L. Cerrada and E. Fleury, Polymer, 2004, 45, 1569-1575.

169 M. Andresen, L. S. Johansson, B. S. Tanem and P. Stenius, Cellulose, 2006, 13, 665-677.

170 Z. Zhang, G. Sèbe, D. Rentsch, T. Zimmermann and P. Tingaut, Chem. Mater., 2014, 26, 2659-2668.

171 G. Siqueira, J. Bras and A. Dufresne, Langmuir, 2010, 26, 402-411.

172 M. V. Biyani, E. J. Foster and C. Weder, ACS Macro Lett., 2013, 2, 236-240.

173 C. Ruiz-Palomero, M. L. Soriano and M. Valcárcel, Analyst, 2015, 140, 3431-3438.

174 D. Roy, M. Semsarilar, J. T. Guthrie and S. Perrier, Chem. Soc. Rev., 2009, 38, 2046-2064.

175 E. Lizundia, E. Meaurio and J. L. Vilas, Multifunctional Polymeric Nanocomposites Based on Cellulosic Reinforcements, Elsevier Inc., 2016, pp. 61-113.

176 D. W. O'Connell, C. Birkinshaw and T. F. O'Dwyer, J. Chem. Technol. Biotechnol., 2006, 81, 1820-1828. 
177 A. M. Donia, A. A. Atia and S. S. Yousif, J. Dispersion Sci. Technol., 2013, 34, 1230-1239.

178 V. K. Gupta, D. Pathania, S. Sharma, S. Agarwal and P. Singh, J. Mol. Liq., 2013, 177, 343-352.

179 R. Kumar, R. K. Sharma and A. P. Singh, Sep. Purif. Technol., 2019, 219, 249-259.

180 A. Carlmark, E. Larsson and E. Malmström, Eur. Polym. J., 2012, 48, 1646-1659.

181 A. Bhatnagar and M. Sain, J. Reinf. Plast. Compos., 2005, 24, 1259-1268.

182 E. S. Abdel-Halim, Arabian J. Chem., 2014, 7, 362-371.

183 M. Roohani, Y. Habibi, N. M. Belgacem, G. Ebrahim, A. N. Karimi and A. Dufresne, Eur. Polym. J., 2008, 44, 2489-2498.

184 V. Favier, H. Chanzy and J. Y. Cavaillé, Macromolecules, 1995, 28, 6365-6367.

185 V. Favier, G. R. Canova, J. Y. Cavaillé, H. Chanzy, A. Dufresne and C. Gauthier, Polym. Adv. Technol., 1995, 6, 351-355.

186 A. P. Mathew and A. Dufresne, Biomacromolecules, 2002, 3, 609-617.

187 M. M. Ruiz, J. Y. Cavaille, A. Dufresne, C. Graillat and J.-F. Gerard, Macromol. Symp., 2001, 169, 211-222.

188 X. Cao, H. Dong and C. M. Li, Biomacromolecules, 2007, 8, 899-904.

189 O. A. Oyedeji and G. B. Osinfade, Afr. J. Environ. Sci. Technol., 2010, 4, 382-387.

190 A. Dufresne and M. R. Vignon, Macromolecules, 1998, 31, 2693-2696.

191 D. W. O'Connell, C. Birkinshaw and T. F. O’Dwyer, Bioresour. Technol., 2008, 99, 6709-6724.

192 S. Hansson, E. Östmark, A. Carlmark and E. Malmström, ACS Appl. Mater. Interfaces, 2009, 1, 2651-2659.

193 A. Carlmark and E. Malmström, J. Am. Chem. Soc., 2002, 124, 900-901.

194 S. Hansson, A. Carlmark, E. Malmström and L. Fogelström, J. Appl. Polym. Sci., 2015, 132(6), 41434.

195 J. Xia and K. Matyjaszewski, Macromolecules, 1997, 30, 7697-7700.

196 M. Kato, M. Kamigaito, M. Sawamoto and T. Higashimura, Macromolecules, 1995, 28, 1721-1723.

197 Fundamentals of an ATRP Reaction - Matyjaszewski Polymer Group - Carnegie Mellon University, https://www.cmu.edu/ maty/chem/fundamentals-atrp/, (accessed 19 September 2020).

198 P. R. Rodrigues and R. P. Vieira, Eur. Polym. J., 2019, 115, 45-58.

199 N. Corrigan, K. Jung, G. Moad, C. J. Hawker, K. Matyjaszewski and C. Boyer, Prog. Polym. Sci., 2020, 101311.

200 M. Semsarilar, V. Ladmiral and S. Perrier, J. Polym. Sci., Part A: Polym. Chem., 2010, 48, 4361-4365.

201 A. D. Jenkins, R. G. Jones and G. Moad, Pure Appl. Chem., 2010, 82, 483-491.

202 D. Roy, J. T. Guthrie and S. Perrier, Soft Matter, 2007, 4, 145-155.

203 D. Roy, J. S. Knapp, J. T. Guthrie and S. Perrier, Biomacromolecules, 2008, 9, 91-99.
204 V. K. Thakur, M. K. Thakur and R. K. Gupta, Int. J. Polym. Anal. Charact., 2013, 18, 495-503.

205 E. Larsson, A. Boujemaoui, E. Malmström and A. Carlmark, RSC Adv., 2015, 5, 77643-77650.

206 R. I. Kureshy, S. Singh, N. ul H. Khan, S. H. R. Abdi, E. Suresh and R. V. Jasra, J. Mol. Catal. A: Chem., 2007, 264, 162-169.

207 H. Lönnberg, K. Larsson, T. Lindström, A. Hult and E. Malmström, ACS Appl. Mater. Interfaces, 2011, 3, 1426-1433.

208 K. Li, J. Huang, H. Gao, Y. Zhong, X. Cao, Y. Chen, L. Zhang and J. Cai, Biomacromolecules, 2016, 17, 1506-1515.

209 S. Harrisson, G. L. Drisko, E. Malmström, A. Hult and K. L. Wooley, Biomacromolecules, 2011, 12, 1214-1223.

210 A. Dufresne, Curr. For. Rep., 2019, 5, 76-89.

211 M. Mariano, N. El Kissi and A. Dufresne, J. Polym. Sci., Part B: Polym. Phys., 2014, 52, 791-806.

212 E. R. Kisin, A. R. Murray, L. Sargent, D. Lowry, M. Chirila, K. J. Siegrist, D. Schwegler-Berry, S. Leonard, V. Castranova, B. Fadeel, V. E. Kagan and A. A. Shvedova, Toxicol. Appl. Pharmacol., 2011, 252, 1-10.

213 S. Il Jeong, S. E. Lee, H. Yang, Y. H. Jin, C. S. Park and Y. S. Park, Mol. Cell. Toxicol., 2010, 6, 373-380.

214 M. Roman, Ind. Biotechnol., 2015, 11, 25-33.

215 S. Camarero-Espinosa, C. Endes, S. Mueller, A. Petri-Fink, B. Rothen-Rutishauser, C. Weder, M. J. D. Clift and E. J. Foster, Fibers, 2016, 4, 21.

216 S. Wang, A. Lu and L. Zhang, Prog. Polym. Sci., 2016, 53, 169-206.

217 R. K. Mishra, A. Sabu and S. K. Tiwari, J. Saudi Chem. Soc., 2018, 22, 949-978.

218 J. Bras, D. Viet, C. Bruzzese and A. Dufresne, Carbohydr. Polym., 2011, 84, 211-215.

219 K. Benhamou, A. Dufresne, A. Magnin, G. Mortha and H. Kaddami, Carbohydr. Polym., 2014, 99, 74-83.

220 P. D. S. C. Mariani, A. P. V. Neto, J. P. da Silva, E. J. B. N. Cardoso, E. Esposito and L. H. InnocentiniMei, J. Polym. Environ., 2007, 15, 19-24.

221 R. M. A. Domingues, M. E. Gomes and R. L. Reis, Biomacromolecules, 2014, 15, 2327-2346.

222 A. Dufresne, Curr. Opin. Colloid Interface Sci., 2017, 29, 1-8. 223 Research on Characterization and Biocompatibility of Nano-bacterial Cellulose Membrane, (accessed 20 January 2021).

224 M. A. Sattar and A. Patnaik, ACS Omega, 2020, 5, 21191-21202. 225 R. M. Sheltami, H. Kargarzadeh, I. Abdullah and I. Ahmad, Handbook of Nanocellulose and Cellulose Nanocomposites, Wiley-VCH Verlag GmbH \& Co. KGaA, Weinheim, Germany, 2017, pp. 523-552.

226 N. Lin and A. Dufresne, Nanoscale, 2014, 6, 5384-5393.

227 M. Mariano, N. El Kissi and A. Dufresne, Polimeros, 2018, 28, 93-102.

228 P. Kumari, G. Pathak, R. Gupta, D. Sharma and A. Meena, Daru, J. Pharm. Sci., 2019, 27, 683-693.

229 X. He, L. Cheng, Y. Wang, J. Zhao, W. Zhang and C. Lu, Carbohydr. Polym., 2014, 111, 683-687. 
230 R. Ccorahua, O. P. Troncoso, S. Rodriguez, D. Lopez and F. G. Torres, Carbohydr. Polym., 2017, 171, 68-76.

231 N. Tazi, Z. Zhang, Y. Messaddeq, L. Almeida-Lopes, L. M. Zanardi, D. Levinson and M. Rouabhia, AMB Express, 2012, 2, 61.

232 M. Oprea and D. M. Panaitescu, Molecules, 2020, 25, 4045.

233 L. Gao, L. Chao, M. Hou, J. Liang, Y. Chen, H. D. Yu and W. Huang, npj Flexible Electron., 2019, 3, 1-8.

234 F. Hoeng, A. Denneulin and J. Bras, Nanoscale, 2016, 8, 13131-13154.

235 G. Chen and Z. Fang, Nanocellulose, Wiley-VCH Verlag GmbH \& Co. KGaA, Weinheim, Germany, 2019, pp. 397-421.

236 S. S. Athukoralalage, R. Balu, N. K. Dutta and N. R. Choudhury, Polymers, 2019, 11.

237 Y. Tan, Y. Liu, W. Chen, Y. Liu, Q. Wang, J. Li and H. Yu, ACS Sustainable Chem. Eng., 2016, 4, 3766-3772.

238 J. Cao, X. Zhang, X. Wu, S. Wang and C. Lu, Carbohydr. Polym., 2016, 140, 88-95.

239 A. Rani, K. Singh, A. S. Patel, A. Chakraborti, S. Kumar, K. Ghosh and P. Sharma, Chem. Phys. Lett., 2020, 738, 136874, DOI: 10.1016/j.cplett.2019.136874.

240 L. Chen, R. M. Berry and K. C. Tam, ACS Sustainable Chem. Eng., 2014, 2, 951-958.

241 S. Azizi, M. B. Ahmad, M. Z. Hussein and N. A. Ibrahim, Synthesis, antibacterial and thermal studies of cellulose nanocrystal stabilized $\mathrm{ZnO}-\mathrm{Ag}$ heterostructure nanoparticles, Molecules, 2013, 18, 6269-6280.

242 S. Wang, X. Zhang, X. Wu and C. Lu, Soft Matter, 2016, 12, 845-852.

243 E. Sharma, D. Vashisht, A. Vashisht, V. K. Vats, S. K. Mehta and K. Singh, Chem. Phys. Lett., 2019, 730, 436-444.
244 D. Vashisht, E. Sharma, M. Kaur, A. Vashisht, S. K. Mehta and K. Singh, Spectrochim. Acta, Part A, 2020, 228, 117773, DOI: 10.1016/j.saa.2019.117773.

245 Q. Zhang, L. Zhang, W. Wu and H. Xiao, Carbohydr. Polym., 2020, 229, 115454.

246 B. N. Nguyen, E. Cudjoe, A. Douglas, D. Scheiman, L. McCorkle, M. A. B. Meador and S. J. Rowan, Macromolecules, 2016, 49, 1692-1703.

247 R. Kumar, R. K. Sharma and A. P. Singh, J. Environ. Chem. Eng., 2019, 7(3), 103088, DOI: 10.1016/j.jece.2019.103088.

248 R. K. Sharma, R. Kumar and A. P. Singh, Sep. Purif. Technol., 2019, 209, 684-697.

249 R. Kumar, R. K. Sharma and A. P. Singh, J. Environ. Chem. Eng., 2018, 6, 6037-6048.

250 A. I. Kryukov, A. L. Stroyuk, N. N. Zin'chuk, A. V. Korzhak and S. Y. Kuchmii, J. Mol. Catal. A: Chem., 2004, 221, 209-221.

251 H. Charreau, E. Cavallo and M. L. Foresti, Carbohydr. Polym., 2020, 237, 116039.

252 S. Tortorella, V. V. Buratti, M. Maturi, L. Sambri, M. C. Franchini and E. Locatelli, Int. J. Nanomed., 2020, 15, 9909-9937.

253 T. H. Tan, H. V. Lee, W. A. Yehya Dabdawb and S. B. B. O. A. A. Hamid, Materials for Biomedical Engineering: Nanomaterialsbased Drug Delivery, Elsevier, 2019, pp. 131-164.

254 E. Reimhult and F. Höök, Sensors, 2015, 15, 1635-1675.

255 S. Sangar, S. Sharma, V. K. Vats, S. K. Mehta and K. Singh, J. Cleaner Prod., 2019, 228, 294-302.

256 R. Kumar, R. K. Sharma and A. P. Singh, J. Mol. Liq., 2017, 232, 62-93.

257 B. Ram and G. S. Chauhan, Chem. Eng. J., 2018, 331, 587-596. 